\title{
Asymmetric supercapacitor based on vanadium disulfide nanosheets as a cathode and carbonized iron cations adsorbed onto polyaniline as an anode
}

\author{
M. N. Rantho, M. J. Madito, F. O. Ochai-Ejeh and N. Manyala* \\ Department of Physics, Institute of Applied Materials, SARChI Chair in Carbon Technology and \\ Materials, University of Pretoria 0028, South Africa. \\ *Corresponding author's email: ncholu.manyala@up.ac.za, Tel.: + (27)12 420 3549; Fax: \\ $+(27) 124202516$
}

\section{Highlights}

- $\mathrm{VS}_{2}$ nanosheets electrode material was synthesized by the hydrothermal method.

- $\mathrm{C}-\mathrm{Fe} / \mathrm{PANI}$ was synthesized on nickel foam by pyrolysis of the iron-PANI mixture.

- The device was fabricated using $\mathrm{VS}_{2}$ as a cathode and C-Fe/PANI as an anode.

- $\mathrm{VS}_{2} / / \mathrm{C}-\mathrm{Fe} / \mathrm{PANI}$ asymmetric device exhibited good electrochemical performance.

\begin{abstract}
$\mathrm{VS}_{2}$ nanosheets electrode material was successfully synthesized by the hydrothermal method, and the electrode material (C-Fe/PANI) based on the carbonization of Fe cations adsorbed onto polyaniline (PANI) was directly synthesized on a nickel foam (current collector) by pyrolysis of the iron-PANI mixture coated on nickel foam in a tube furnace under the $\mathrm{N}_{2}$ atmosphere. The structural and morphological characterization of the as-synthesized electrode materials was carried out using X-ray diffraction (XRD), Raman spectroscopy, Fourier transform infrared (FTIR) spectroscopy and scanning electron microscopy (SEM). The electrochemical behavior of each working electrode was analyzed in a three-electrode cell configuration using $6 \mathrm{M} \mathrm{KOH}$ electrolyte, and thereafter, a hybrid (asymmetric) device was successfully fabricated using $\mathrm{VS}_{2}$ nanosheets as the positive electrode and C-Fe/PANI as a negative electrode. The fabricated $\mathrm{VS}_{2} / / \mathrm{C}-\mathrm{Fe} / \mathrm{PANI}$ asymmetric device was found to perform at a high applied potential difference of $1.7 \mathrm{~V}$ in $6 \mathrm{M} \mathrm{KOH}$. At a current density of $2 \mathrm{~A} \mathrm{~g} \mathrm{~g}^{-1}$, this device exhibited high energy and power densities of $27.8 \mathrm{Wh} \mathrm{kg}^{-1}$ and $2991.5 \mathrm{~W} \mathrm{~kg}^{-1}$ respectively. In addition, a $\mathrm{VS}_{2} / / \mathrm{C}-\mathrm{Fe} / \mathrm{PANI}$
\end{abstract}


device showed excellent cycling stability with $95 \%$ capacity retention over 10000 galvanostatic charge-discharge cycles at a current density of $5 \mathrm{~A} \mathrm{~g}^{-1}$.

KEYWORDS: Supercapacitor; Asymmetric device; $\mathrm{VS}_{2}$ nanosheets; Iron-PANI; Energy storage

\section{INTRODUCTION}

Supercapacitors (SCs) which are also referred to as electrochemical capacitors (ECs) have attracted great interest for the important application in the area of electrochemical energy storage because of increasing demand for digital communication, electric vehicles and other electric devices at high pulse power level [1-7]. Since, SCs are high power-delivery storage devices which are able to discharge in a shorter time by exploiting their fast surface or near surface reactions and delivering high power compared to conventional batteries [2,8-10]. Though, SCs are high power-delivery storage devices (have high power density) they have low energy density especially compared to rechargeable batteries (Li-ion batteries) [2,11]. Accordingly, research focus in SCs is on improving their energy density (i.e. $\sim 5-8 \mathrm{Wh} \mathrm{kg}^{-1}$ ) without compromising their high power density (i.e. $\sim 5-30 \mathrm{~kW} \mathrm{~kg}^{-1}$ ), unlike in rechargeable batteries which already have high energy density in the range of $120-200 \mathrm{Wh} \mathrm{kg}^{-1}$, the focus will be on improving the power density which is in the range of $0.4-3 \mathrm{~kW} \mathrm{~kg}^{-1}[2,8,9,12]$. Recently, asymmetric (hybrid) systems have been explored to increase the operating electrode potential to improve the energy density of the SCs. Generally, the behavior of the SCs is mainly influenced by the charge storage mechanism which is divided into two classifications, namely, the electric double layer capacitors (EDLCs) and pseudocapacitors [1,2,13]. In EDLCs, the predominant energy storage is achieved by double-layer capacitance, and in this charge storage process, there is no transfer of charges. On the other hand, in pseudocapacitors, the electrical energy is stored faradaically by electron charge transfer between electrode and electrolyte [2]. This is accomplished through electrosorption, reduction-oxidation reactions (redox reactions), and intercalation processes, called pseudocapacitance. 
The electrochemical capacitors have three main categories of electrode materials which are carbon materials such as carbon nanotubes, transition metal oxides (e.g. $\mathrm{MnO}_{2}$ and $\mathrm{RuO}_{2}$ ), and electrochemically conducting polymers, for instance, polyaniline (PANI) and polypyrrole [1417]. Among various pseudocapacitive materials that have been studied, PANI has attracted great attention as one of the most promising pseudocapacitive polymer material suitable for the next generation of supercapacitors. This is due to its attractive properties such as high pseudocapacitance, light weight, low cost, controllable electrical conductivity, high energy density, facile synthesis, and environmental friendliness [18-21]. PANI is often used as electrode material for supercapacitors and it has three oxidation states (leucoemeraldine, emeraldine salt, and pernigraniline) which contribute to its high specific capacitance [22]. Among its three oxidation states, the emeraldine salt has lower electronic conductivity than that of typical metals [23]. The need to develop high-performance SCs has led to the incorporation of metals and metal oxide particles into PANI to enhance its electronic conductivity [24]. It has been shown that ironcontaining nitrogen-doped graphitic carbon materials, carbonized PANI in particular, achieve high electrocatalytic performance and exhibit high cycling stability [15,16]. Generally, carbonaceous materials with Fe cations have shown enhanced electrochemical performance as the negative electrode materials for SCs, including iron oxides and hydroxides [25-27]. Therefore, the synthesis of carbonized Fe-PANI hybrid material is promising for achieving highperformance SCs. In this study, Fe cations are found to be interesting since they can easily adsorb onto PANI by the complexation and electrostatic interactions due to the active binding sites present in functional groups on PANI [18,28-30].

Until now, transition metal oxides/sulfides and layered transition-metal dichalcogenides (TMDs) such as $\mathrm{MoS}_{2}, \mathrm{VS}_{2}, \mathrm{WS}_{2}, \mathrm{FeS}_{2}, \mathrm{CoS}_{2}$, and $\mathrm{NiS}_{2}$ have been successfully established as new paradigm in the chemistry of nanomaterials especially for nanotubes and fullerene-like nanostructures as well as the graphene analogs and have been extensively investigated as the positive electrode materials for SCs due to their high faradic capacitance [31-35]. On the other hand, $\mathrm{VS}_{2}$ has not received much attention in two electrode supercapacitor devices. However, it has been investigated for applications in SCs due to its promising electrochemical performance. Recently, Feng et al. [36], reported all-in-solution route to synthesize $\mathrm{VS}_{2}$ phase for the first time, taking advantage of an intermediate intercalated compound precursor of $\mathrm{VS}_{2} \cdot \mathrm{NH}_{3}$. This report clearly demonstrated that $\mathrm{VS}_{2}$ nanosheets are highly conductive and have a high specific 
capacitance, showing promising signs for 2D material to be utilized in energy storage devices. Masikhwa et al. [37], reported the design of an asymmetric supercapacitor based on 3D interconnected activated carbon as the negative electrode and mesoporous $\mathrm{VS}_{2}$ nanosheets as the positive electrode material. The report suggests that pairing hybrid materials could be an excellent method to produce SCs with high energy and power densities.

Although studies about $\mathrm{VS}_{2}$ electrode for supercapacitor applications have been reported in the literature, there are rare studies done on the binder-free electrode material based on carbonized Fe cations adsorbed onto PANI (C-Fe/PANI) and until now there are no reports on $\mathrm{VS}_{2} / / \mathrm{C}$ Fe/PANI asymmetric cell device. Herein, we report on asymmetric supercapacitor based on $\mathrm{VS}_{2}$ nanosheets as a cathode and C-Fe/PANI as an anode. This study focuses on structural, and morphological characterization of the as-synthesized electrode materials and the electrochemical properties of $\mathrm{VS}_{2} / / \mathrm{C}$-Fe/PANI asymmetric device. The $\mathrm{VS}_{2} / / \mathrm{C}-\mathrm{Fe} / \mathrm{PANI}$ asymmetric device was found to perform at a high applied potential difference of $1.7 \mathrm{~V}$ in $6 \mathrm{M} \mathrm{KOH}$. At a high current density of $2 \mathrm{~A} \mathrm{~g}^{-1}$, this device exhibited energy and power densities of $27.8 \mathrm{Wh} \mathrm{kg}^{-1}$ and 2991.5 $\mathrm{W} \mathrm{kg}^{-1}$ respectively. In addition, a $\mathrm{VS}_{2} / / \mathrm{C}-\mathrm{Fe} / \mathrm{PANI}$ device showed excellent cycling stability with $95 \%$ capacity retention for 10000 galvanostatic charge-discharge cycles at a current density of $5 \mathrm{~A} \mathrm{~g}^{-1}$.

\section{EXPERIMENTAL}

\subsection{Materials}

All the reagents used in this work are of analytical grade and were used as received without further purification. For $\mathrm{VS}_{2}$ nanosheets synthesis: Sodium orthovanadate $\left(1 \mathrm{mM} \mathrm{Na} \mathrm{VO}_{4}\right.$, purity $99.98 \%$ ) and thioacetamide ( $5 \mathrm{mM} \mathrm{C}_{2} \mathrm{H}_{5} \mathrm{NS}$, purity $\geq 99 \%$ ), were purchased from Sigma Aldrich. For C-Fe/PANI synthesis: Aniline hydrochloride $\left(\mathrm{C}_{6} \mathrm{H}_{5} \mathrm{NH}_{2} \cdot \mathrm{HCl}\right.$, purity $\left.\geq 99 \%\right)$, ammonium persulphate $\left(\left(\mathrm{NH}_{4}\right)_{2} \mathrm{~S}_{2} \mathrm{O}_{8}\right.$, purity $\left.\geq 99 \%\right)$ and iron nitrate nonahydrate $\left(\mathrm{Fe}\left(\mathrm{NO}_{3}\right)_{3} \cdot 9 \mathrm{H}_{2} \mathrm{O}\right.$, purity $\geq 99.95 \%$ ) were also purchased from Sigma Aldrich. Polycrystalline nickel foam (Ni-F) used as a

current collector which is a 3D scaffold template with an areal density of $420 \mathrm{~g} \mathrm{~m}^{2}$ and thickness of $1.6 \mathrm{~mm}$ was purchased from Alantum (Munich, Germany). 


\subsection{Synthesis of $\mathrm{VS}_{2}$ nanosheets using hydrothermal method}

$\mathrm{VS}_{2}$ nanosheets were synthesized by the hydrothermal method as shown in scheme 1(a). In the synthesis, $1.65 \mathrm{~g}$ of $1 \mathrm{mM} \mathrm{Na}_{3} \mathrm{VO}_{4}$ and $3.37 \mathrm{~g}$ of $5 \mathrm{mM} \mathrm{C}_{2} \mathrm{H}_{5} \mathrm{NS}$ were dissolved in $120 \mathrm{~mL}$ of deionized water and stirred for $1 \mathrm{~h}$ at room temperature using a magnetic stirrer. After stirring, the resultant solution was transferred into a sealed, $150 \mathrm{~mL}$ Teflon-lined, stainless-steel autoclave and kept at a temperature of $160{ }^{\circ} \mathrm{C}$ for $24 \mathrm{~h}$ and then cooled naturally down to the room temperature. Subsequently, the obtained precipitate was filtered and washed with deionized water several times and dried at $60{ }^{\circ} \mathrm{C}$ overnight. Finally, the recovered product of $\mathrm{VS}_{2}$ nanosheets was obtained as displayed by micrograph in scheme 1(a).

(a)

(b)

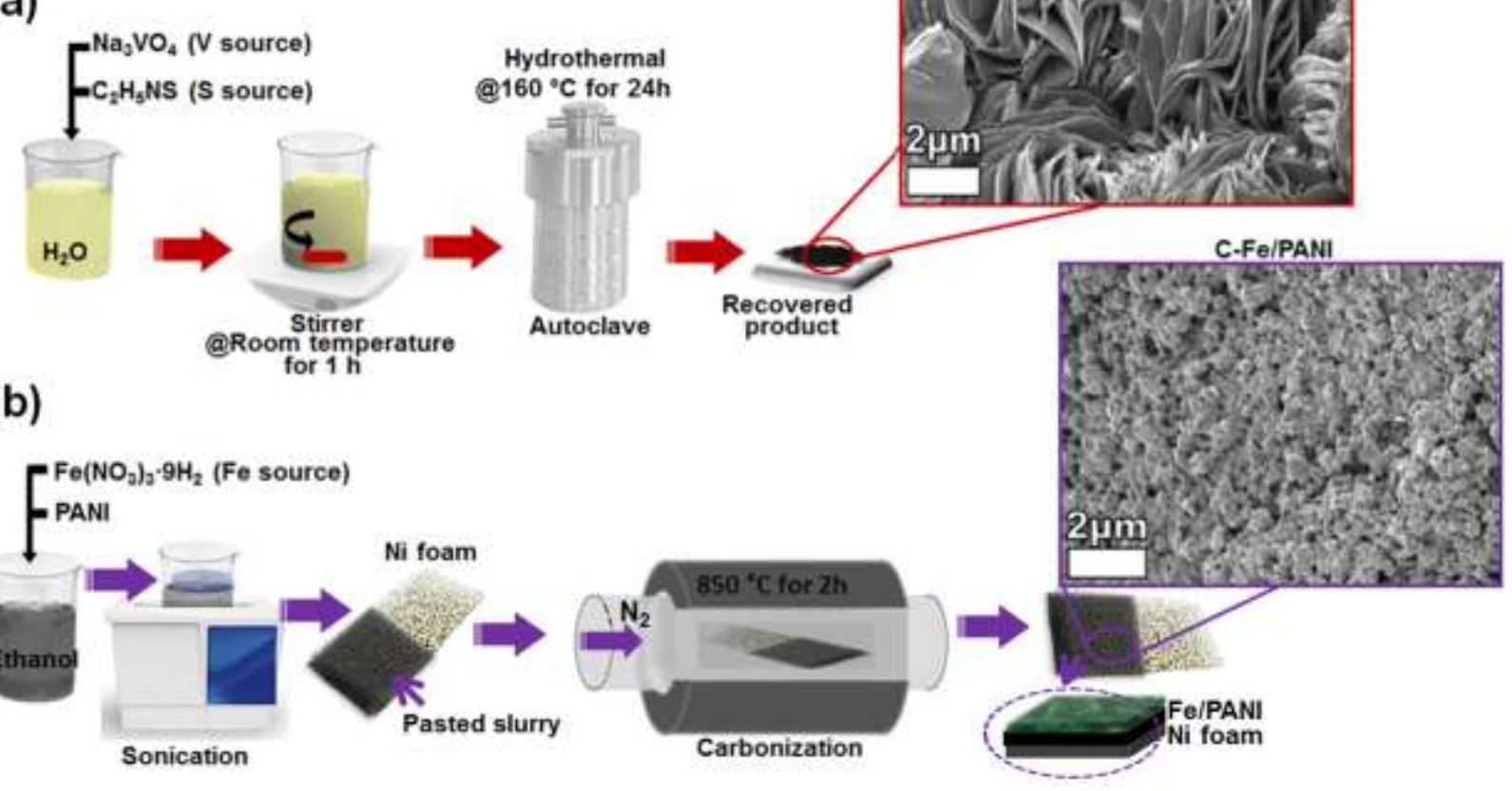

Scheme 1. Schematic illustration of the synthesis route for (a) $\mathrm{VS}_{2}$ nanosheets and (b) carbonized iron cations adsorbed onto polyaniline (C-Fe/PANI).

\subsection{Synthesis of C-Fe/PANI}

For PANI synthesis: $0.2 \mathrm{M}$ aniline hydrochloride was added to a $50 \mathrm{ml}$ solution of $1.0 \mathrm{M} \mathrm{HCl}$, and in a separate beaker $0.25 \mathrm{M}$ solution of ammonium persulphate was added to $1.0 \mathrm{M} \mathrm{HCl}$. 
The prepared solutions were kept for $1 \mathrm{~h}$ at room temperature, thereafter, they were mixed and stirred for about an hour and left to polymerize. After polymerization, PANI precipitate was collected on a filter (after been washed several times with $100 \mathrm{ml}$ of $0.2 \mathrm{M} \mathrm{HCl}$, and acetone) and dried at $60{ }^{\circ} \mathrm{C}$ overnight. Furthermore, PANI was used as a substrate for adsorbing $\mathrm{Fe}$ cations. Briefly, $0.2 \mathrm{~g}$ of $\mathrm{Fe}\left(\mathrm{NO}_{3}\right)_{3} \cdot 9 \mathrm{H}_{2} \mathrm{O}$ and $0.0125 \mathrm{~g}$ of PANI were dissolved in $50 \mathrm{~mL}$ of ethanol and sonicated in ultra-sonication bath until the ethanol was almost completely evaporated. Thereafter, the slurry was coated on nickel foam (current collector) which was loaded in a tube furnace and heated to $850^{\circ} \mathrm{C}$ and pyrolyzed for $2 \mathrm{~h}$ under the $\mathrm{N}_{2}$ atmosphere. After pyrolysis, the as-synthesized sample which shows homogeneously dispersed nanograin particles (Scheme 1(b)) was used as the negative electrode (i.e. without a binder).

\subsection{Structural, and morphological characterization}

The crystallite structure analysis of the as-synthesized $\mathrm{VS}_{2}$ and C-Fe/PANI materials was carried out using X-ray diffraction (XRD) XPERTPRO diffractometer (PANalytical BV, Netherlands) with theta/2 theta geometry, operating with a cobalt (Co) tube at $50 \mathrm{kV}$ and $30 \mathrm{~mA}$. A T64000 micro-Raman spectrometer (HORIBA Scientific, Jobin Yvon Technology) with a $514 \mathrm{~nm}$ laser wavelength and spectral acquisition time of $120 \mathrm{~s}$ was used to characterize the as-synthesized electrode materials. The Raman system laser power was set as low as $3 \mathrm{~mW}$ in order to minimize heating effects. Fourier transform infrared (FT-IR) spectroscopy performed in the range of 400 to $4000 \mathrm{~cm}^{-1}$ using Perkin Elmer Spectrum RX I FT-IR system was used to characterize $\mathrm{VS}_{2}$ and CFe/PANI materials. The scanning electron microscopy (SEM) images were obtained using a Zeiss Ultra Plus 55 field emission scanning electron microscope (FE-SEM) operated at $2.0 \mathrm{kV}$ to obtain the morphology of the $\mathrm{VS}_{2}$ and $\mathrm{C}-\mathrm{Fe} / \mathrm{PANI}$ materials.

\subsection{Electrochemical characterization}

All electrochemical analysis were carried out on a Biologic VMP-300 potentiostat (Knoxville TN 37,930, USA) controlled by the EC-Lab V10.37 software at room temperature. In the threeelectrode system, a glassy carbon plate was used as the counter electrode and $\mathrm{Ag} / \mathrm{AgCl}(3 \mathrm{M}$ $\mathrm{KCl})$ electrode served as the reference electrode. The working electrode ( $\mathrm{VS}_{2}$ nanosheets) was prepared by coating a mixture of $80 \mathrm{wt} \%$ active material, $10 \mathrm{wt} \%$ carbon black and $10 \mathrm{wt} \%$ polyvinylidene fluoride (PVDF) binder dispersed in N-methylpyrrolidone (NMP) 
solution onto a piece of nickel foam $\left(1 \times 1 \mathrm{~cm}^{2}\right)$. After coating, the as-synthesized electrode was dried at $60{ }^{\circ} \mathrm{C}$ overnight, and thereafter, the coated active material was pressed onto the nickel foam under a pressure of $30 \mathrm{MPa}$. However, the other working electrode (C-Fe/PANI) was prepared without a binder as discussed in the synthesis method (Scheme 1(b)). Briefly, a mixture of Fe and PANI dissolved in ethanol was sonicated until the ethanol was almost completely evaporated, and thereafter, the slurry was coated on nickel foam (i.e. on both sides of the foam for three electrode and on one side for two electrode measurements) which was loaded in a tube furnace and heated to $850{ }^{\circ} \mathrm{C}$ and pyrolyzed for $2 \mathrm{~h}$ under the $\mathrm{N}_{2}$ atmosphere. After pyrolysis, the as- synthesized sample was used as the negative electrode. The electrochemical measurements of $\mathrm{VS}_{2}$ and $\mathrm{C}-\mathrm{Fe} / \mathrm{PANI}$ electrodes were carried out in the three-electrode system in $6 \mathrm{M} \mathrm{KOH}$ aqueous electrolyte solution. Cyclic voltammetry (CV) was performed at scan rates of 5 to 100 $\mathrm{mV} \mathrm{s}^{-1}$ in the applied potential range of $0.0-0.5 \mathrm{~V}$ vs. $\mathrm{Ag} / \mathrm{AgCl}$ and 0.0 to $-1.2 \mathrm{~V} \mathrm{vs}$. $\mathrm{Ag} / \mathrm{AgCl}$ for the positive and negative electrode, respectively. The galvanostatic charge/discharge (GCD) curves for both working electrodes were tested. The electrochemical impedance spectroscopy (EIS) was measured in an open circuit potential over a frequency range of $10 \mathrm{mHz}$ to $100 \mathrm{kHz}$. The electrochemical analysis of the active material was also evaluated in a two-electrode asymmetric device. In the two-electrode asymmetric device $\left(\mathrm{VS}_{2} / / \mathrm{C}-\mathrm{Fe} / \mathrm{PANI}\right), \mathrm{VS}_{2}$ and C$\mathrm{Fe} / \mathrm{PANI}$ electrode served as a positive and negative electrode, respectively.

\section{RESULTS AND DISCUSSION}

\subsection{Structural and morphological characterization}

Figure 1(a) shows the XRD pattern of the as-synthesized $\mathrm{VS}_{2}$ sample which shows the characteristic diffraction peaks of $\mathrm{VS}_{2}$ with clear main two diffraction peaks corresponding to (001) and (011). The XRD pattern agrees with the one reported in the literature of $\mathrm{VS}_{2}$ nanosheets synthesized using the hydrothermal method [36]. In figure 1(a), the diffraction peaks were indexed using the matching Inorganic Crystal Structure Database (ICSD) card no. 86519 with chemical formula $\mathrm{VS}_{2}$, space-group $P-3 m 1$ and cell parameters $a=3.221 \AA$ and $c=5.755$ $\AA$. From figure 1(b) it can be seen that vanadium disulfide is a hexagonal layered transition metal dichalcogenide with each layer composing of one vanadium sheet sandwiched between the two sulfur sheets. The sandwiches are separated by van der Waals gap [38]. The unit cell and the 
molecule of the $\mathrm{VS}_{2}$ shown figure 1(b) are based on Crystallographic Information File (CIF) of ICSD card no. 86519.
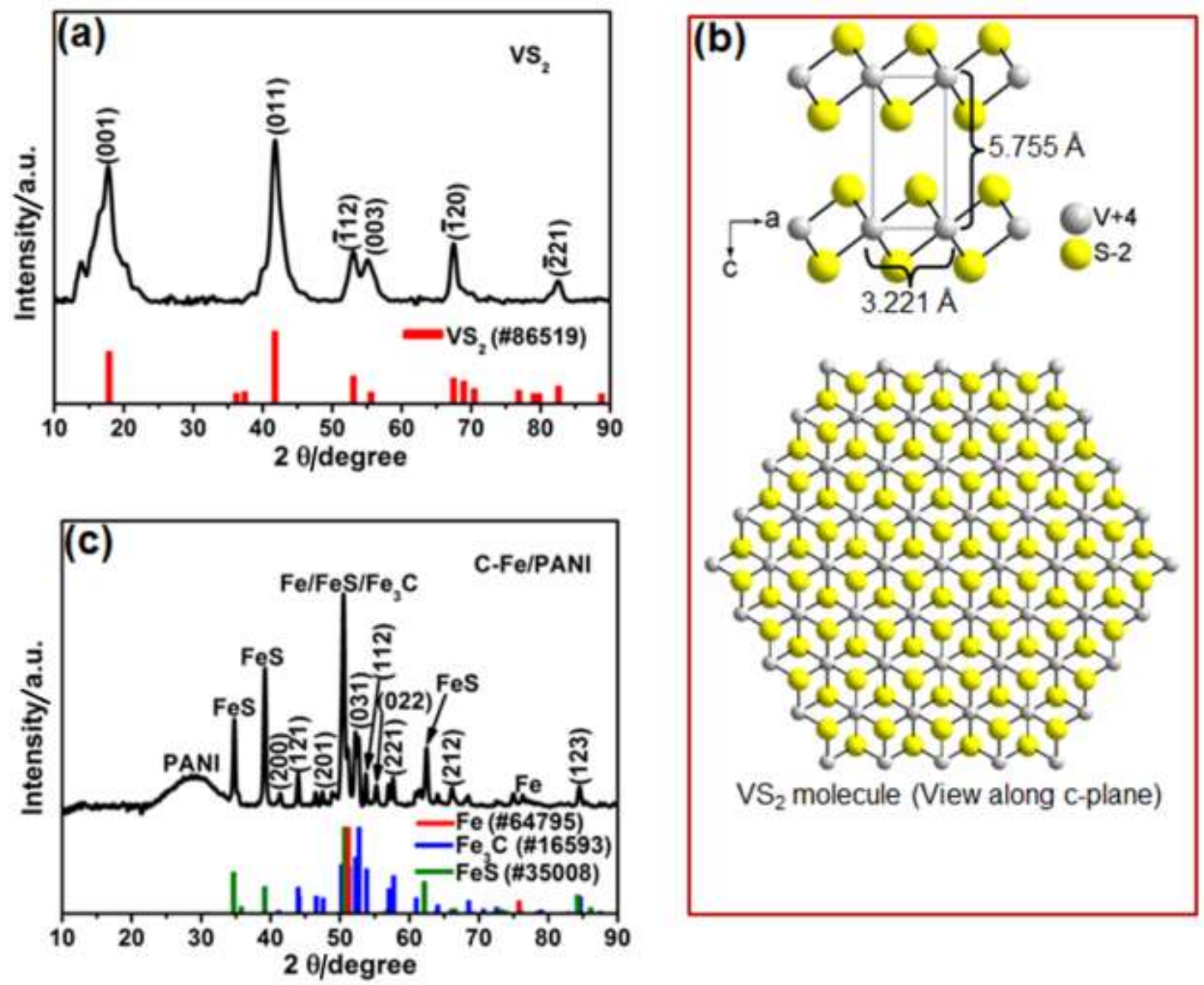

$\mathrm{VS}_{2}$ molecule (View along c-plane)

Figure 1. (a) The XRD pattern of the as-synthesized $\mathrm{VS}_{2}$ nanosheets and the matching ICSD card. (b) The unit cell and the molecule of the $\mathrm{VS}_{2}$ based on CIF of the matching ICSD card. (c) The XRD pattern of the as-synthesized C$\mathrm{Fe} / \mathrm{PANI}$ without current collector and the matching ICSD cards for $\mathrm{Fe}, \mathrm{Fe}_{3} \mathrm{C}$ and $\mathrm{FeS}$.

Figure S1 (supporting information) shows the XRD of the as-synthesized C-Fe/PANI sample which displays very strong diffraction peaks of the $\mathrm{Ni}$ (current collector) which suppresses the weak diffraction peaks of the active material. To avoid the Ni diffraction, the C-Fe/PANI was prepared without Ni foam and figure 1(c) shows the XRD of the sample. The diffraction peaks for C-Fe/PANI sample were indexed using the matching ICSD card no. 16593 with chemical 
formula $\mathrm{Fe}_{3} \mathrm{C}$, crystal system: orthorhombic and space-group: $P$ n $m a$. In addition, the other diffraction peaks that did not match the ICSD card no. 16593 for $\mathrm{Fe}_{3} \mathrm{C}$ were found to match the ICSD card no. 35008 for FeS (crystal system: orthorhombic and space-group: $P$ n $m a$.) which suggests that during the pyrolysis process the degradation of ammonium persulphate from PANI synthesis generated iron sulfide. Furthermore, A diffraction peak at about $52^{\circ}$ could also be due to metallic $\mathrm{Fe}$ in addition to $\mathrm{Fe}_{3} \mathrm{C}$ and $\mathrm{FeS}$, because during the pyrolysis process, $\mathrm{Fe}$ cations could be reduced to metallic iron by the reaction with pyrolytic carbon from PANI [39]. A broad diffraction peak at about $30^{\circ}$ (PANI) is assigned to the XRD graphitic plane (002), indicating a graphitization of carbon material. In fact, the phenyl groups of PANI easily produce a graphitic structure during pyrolysis, thus leading to enhanced electrical conductivity [40].

The chemical structure of the as-synthesized $\mathrm{VS}_{2}$ was investigated using the Raman and FTIR vibration spectra as shown in figure 2(a). The Raman spectrum of $\mathrm{VS}_{2}$ reveals vanadium disulfide characteristic vibration bands at approximately 140, 285 and $405 \mathrm{~cm}^{-1}$ which are $\mathrm{E}_{1 \mathrm{~g}}$, $\mathrm{E}_{2 \mathrm{~g}}$ and $\mathrm{A}_{1 \mathrm{~g}}$ respectively, corresponding to the in-plane (E) and out-of-plane (A) modes of $\mathrm{S}-\mathrm{V}-$ $\mathrm{S}$ (Figure 2(b)). Similar characteristic vibration bands were previously observed for $2 \mathrm{H}-\mathrm{TaS}$ by Sugai et al. [41]. In fact, the Raman signal of $\mathrm{VS}_{2}$ is similar to that of other group $\mathrm{V}$ metal sulfides [41,42]. FTIR vibration spectrum of $\mathrm{VS}_{2}$ (Figure 2(a)) shows the characteristic V-S stretching vibration band of $\mathrm{VS}_{2}$ below $600 \mathrm{~cm}^{-1}$ and in the range of $\sim 800-4000 \mathrm{~cm}^{-1}$ the observed vibration bands may originate from the oxidation of $\mathrm{VS}_{2}$ and absorbed gas molecules on the surface of $\mathrm{VS}_{2}$ nanosheets during exposure to the atmosphere.

Similarly, the chemical structure of the as-synthesized C-Fe/PANI was also investigated using the Raman and FTIR vibration spectra (Figure 2(c)). The Raman spectrum of C-Fe/PANI reveals features of the graphitized carbon material, namely the $\mathrm{D}$ band $\left(\sim 1350 \mathrm{~cm}^{-1}\right)$ which is a breathing mode of sixfold rings $\left(\mathrm{A}_{1 \mathrm{~g}}\right.$ symmetry) and becomes active in the presence of disorder in the carbon lattice sites, and $\mathrm{G}$ band $\left(\sim 1602 \mathrm{~cm}^{-1}\right)$ which involves in-plane bond stretching displacements of $\mathrm{sp}^{2}$ carbon atoms ( $\mathrm{E}_{2 \mathrm{~g}}$ symmetry) (Figure 2(d)) [43]. The observed vibration bands in the range of $1240-1700 \mathrm{~cm}^{-1}$ are attributed to PANI functional groups. Generally, the Raman spectrum of PANI reveals functional groups at approximately $1610 \mathrm{~cm}^{-1}(\mathrm{C}-\mathrm{C}$ stretching $), \quad 1585 \mathrm{~cm}^{-1} \quad(\mathrm{C}=\mathrm{C} \quad$ stretching $), \quad 1490 \mathrm{~cm}^{-1} \quad(\mathrm{C}=\mathrm{N} \quad$ stretching $), \quad 1412 \mathrm{~cm}^{-1} \quad(\mathrm{C}-\mathrm{C}$ stretching), $1346 \mathrm{~cm}^{-1}$ (C-N stretching), $1210 \mathrm{~cm}^{-1}$ (C-N stretching) [18,30]. Furthermore, the 

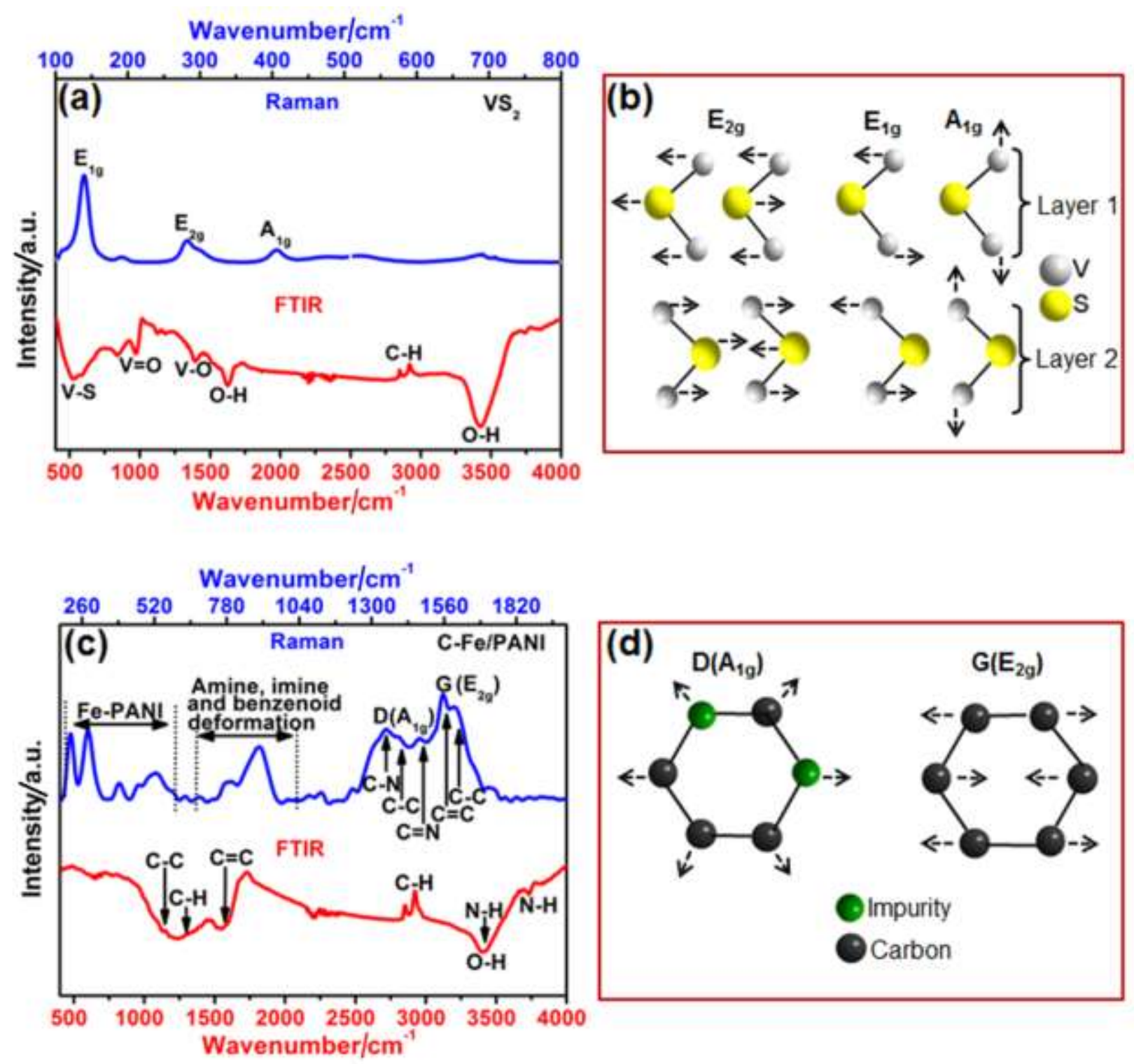

Figure 2. (a) The Raman and FTIR vibration spectrum of the as-synthesized $\mathrm{VS}_{2}$ nanosheets, and (b) the schematic view of the corresponding Raman vibrational modes. (c) The Raman and FTIR vibration spectrum of the assynthesized C-Fe/PANI, and (d) the schematic view of the breathing mode of sixfold rings ( $\mathrm{A}_{1 \mathrm{~g}}$ symmetry) and the in-plane bond stretching displacements of $\mathrm{sp}^{2}$ carbon atoms $\left(\mathrm{E}_{2 \mathrm{~g}} \mathrm{symmetry}\right)$.

vibration bands at about 781 and $895 \mathrm{~cm}^{-1}$ are associated with the deformation of amine, imine, and benzenoid/quinoid rings [18], and the bands at about 215, 280, 395, and $505 \mathrm{~cm}^{-1}$ originate from $\mathrm{Fe}-\mathrm{PANI}$ (e.g. Fe-C, Fe-N, Fe-S, etc.) vibration bands which are similar to those reported by Pradhan et al. [44]. In view of the FTIR spectra of C-Fe/PANI, the functional groups of PANI 
are observable at the IR bands of $1583 \mathrm{~cm}^{-1}$ ( $\mathrm{C}=\mathrm{C}$ stretching of the quinoid ring), $1296 \mathrm{~cm}^{-1}$ (C$\mathrm{H}$ in-plane bending) and $1139 \mathrm{~cm}^{-1}$ (C-C stretching) [18]. In addition, the functional groups of PANI are also found at $\sim 3715$ and $3420 \mathrm{~cm}^{-1}$ (N-H stretching), and $2922 \mathrm{~cm}^{-1}$ (C-H stretching), however, the broad vibration band in the range of $3010-3680 \mathrm{~cm}^{-1}$ is usually assigned to $\mathrm{O}-\mathrm{H}$ stretching vibrations $[18,45-47]$. No characteristic peaks of $\mathrm{Fe}-\mathrm{S}$ or $\mathrm{Fe}-\mathrm{O}$ vibrations at $\sim 500$ $600 \mathrm{~cm}^{-1}$ are observed.

The morphology of as-synthesized layered structure of $\mathrm{VS}_{2}$ was examined using SEM and the results are shown in figure 3(a) and (b) at low and high magnification respectively. It can be seen from these figures that the sample is composed of a large number of nanosheets. The morphology of the C-Fe/PANI sample was also examined using SEM and the results are shown in figure 3(c) and (d). At low magnification, in figure 3(c), it can be seen that the crystallites are agglomerated and well distributed all over the sample surface suggesting that $\mathrm{Fe}$ cations adsorbed onto polyaniline are uniformly dispersed on the surface of the C-Fe/PANI sample.
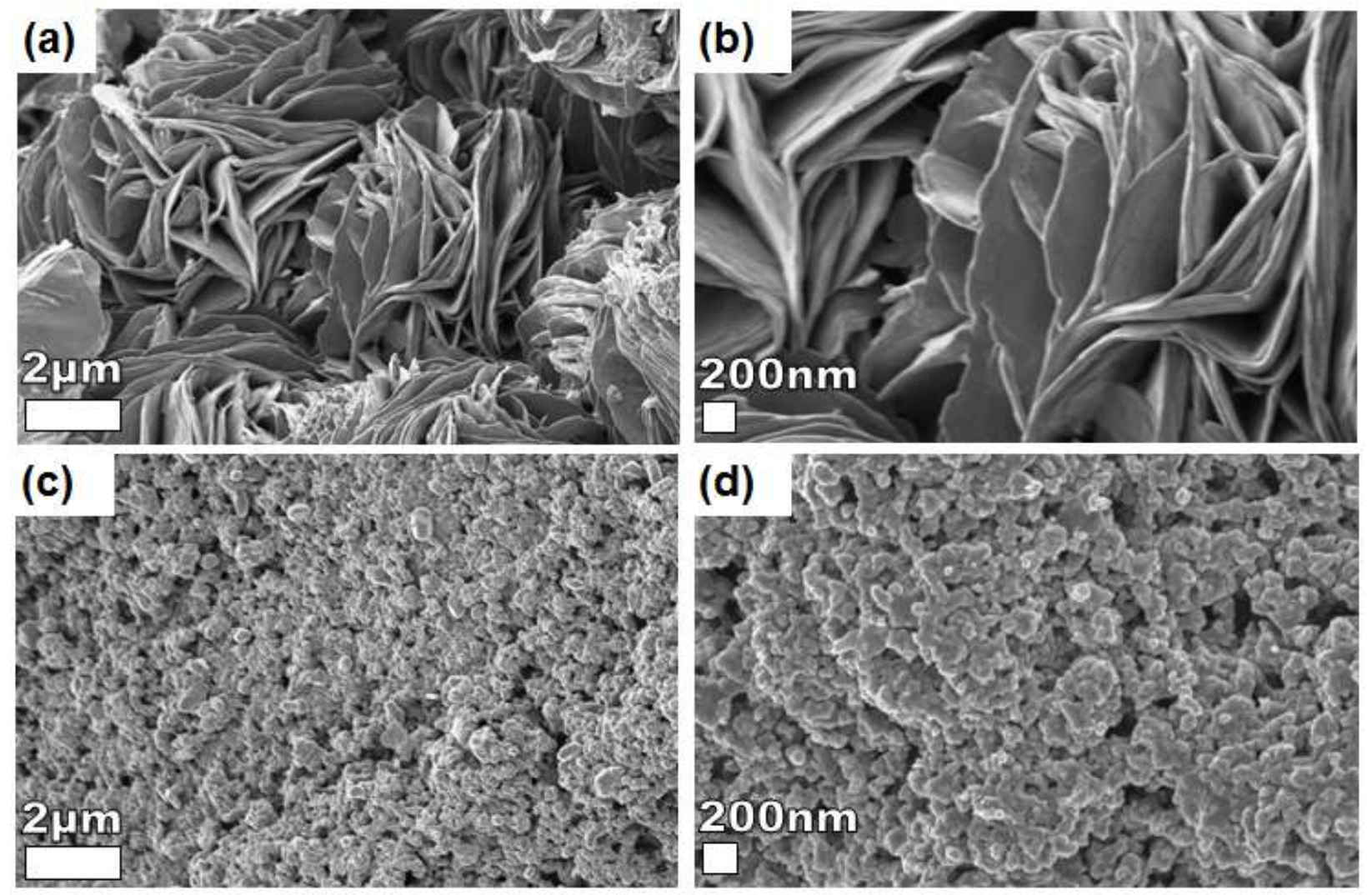

Figure 3. (a) Low and (b) high magnification SEM images of the as-synthesized layered structure of $\mathrm{VS}_{2}$. (c) Low and (d) high magnification SEM images of as-synthesized C-Fe/PANI. 


\subsection{Electrochemical characterization}

Before fabricating a two-electrode asymmetric device based on $\mathrm{VS}_{2}$ nanosheets as a cathode and $\mathrm{C}-\mathrm{Fe} / \mathrm{PANI}$ as an anode, the electrochemical performances of the $\mathrm{VS}_{2}$ and $\mathrm{C}-\mathrm{Fe} / \mathrm{PANI}$ electrodes were evaluated in three-electrode cell configuration. Firstly, the cyclic voltammetry (CV) of the cathode ( $\mathrm{VS}_{2}$ nanosheets) was evaluated in three-electrode cell configuration using $1 \mathrm{M} \mathrm{KOH}$, $6 \mathrm{M} \mathrm{KOH}$ and $1 \mathrm{M} \mathrm{Na}_{2} \mathrm{SO}_{4}$ electrolytes, as shown in figure 4(a) (also see figure S2 (supporting information)). From the figure it can be seen that $\mathrm{VS}_{2}$ electrode performs better (has a highest current response) in $\mathrm{KOH}$ than in $\mathrm{Na}_{2} \mathrm{SO}_{4}$, this is due to the difference in the hydrated radius of $\mathrm{K}^{+}$ions $(0.331 \mathrm{~nm})$ and $\mathrm{Na}^{+}$ions $(0.358 \mathrm{~nm})$. The lower hydrated radius of $\mathrm{K}^{+}$ions favors enhanced ionic mobility and interaction with the electrode material. Furthermore, it is worth mentioning that the reported conductivity of $\mathrm{K}^{+}$ions is higher than that of $\mathrm{Na}^{+}$ions at room temperature [48]. $\mathrm{K}^{+}$ions acquire small charge density, i.e. weak solvation interactions with the water molecule that favors easier polarization during the de-solvation processes. This causes an easy passage of $\mathrm{K}^{+}$ions into the electrode during the redox reactions. In addition, the $\mathrm{OH}^{-}$anion has the highest ionic conductivity among anions [48]. The high concentration of $6 \mathrm{M} \mathrm{KOH}$ also increases the number of ions and therefore the ionic conductivity of the electrolyte. $\mathrm{The} \mathrm{VS}_{2}$ in $\mathrm{KOH}$ electrolyte also shows faradic behavior which leads to much higher specific capacitance compared to using $\mathrm{Na}_{2} \mathrm{SO}_{4}$. In figure 4(b) the $\mathrm{CV}$ curves of $\mathrm{VS}_{2}$ and $\mathrm{Ni}-\mathrm{F}$ are shown, to illustrate that Ni-F has no obvious influence in the observed redox peaks (a reduction and oxidation peaks at $0.15 \mathrm{~V}$ and $0.31 \mathrm{~V}$ respectively) of $\mathrm{VS}_{2}$ which clearly shows that these peaks are from $\mathrm{VS}_{2}$
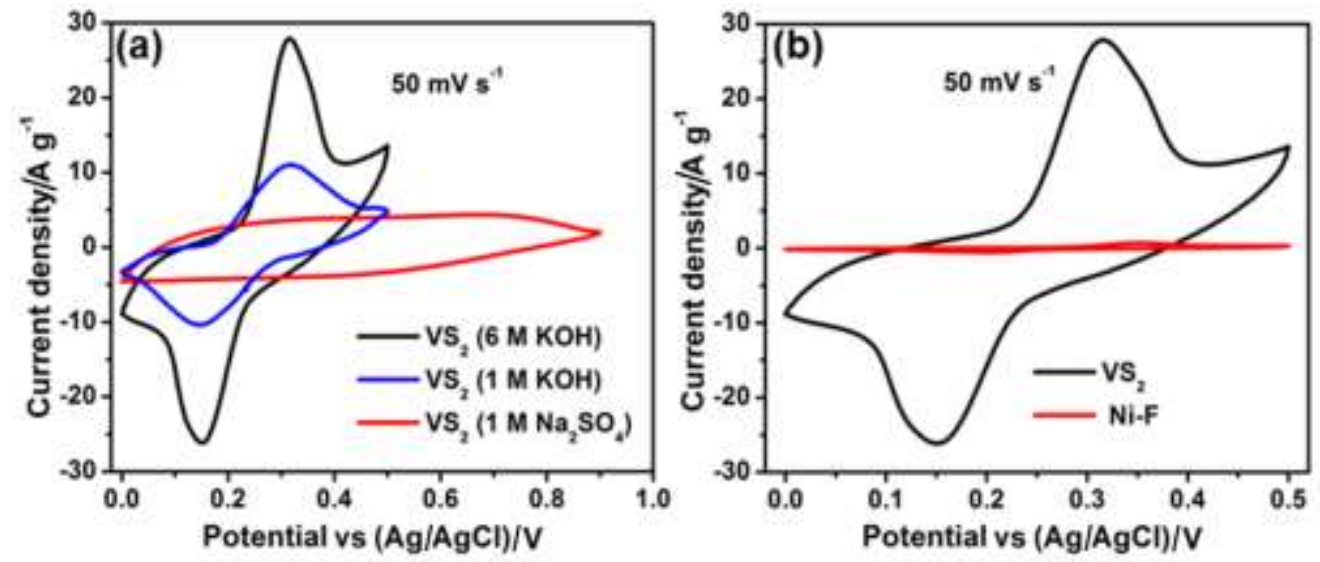

Figure 4. (a) $\mathrm{CV}$ curves of $\mathrm{VS}_{2}$ in different electrolytes at a scan rate of $50 \mathrm{mV} \mathrm{s}^{-1}$. (b) $\mathrm{CV}$ curves of $\mathrm{VS}_{2}$ and $\mathrm{Ni}$ foam (Ni-F) at a scan rate of $50 \mathrm{mV} \mathrm{s}^{-1}$. 
The $\mathrm{CV}$ curves of $\mathrm{VS}_{2}$ electrode are shown in figure 5(a) at different scan rates of 5, 10, 20, 50, and $100 \mathrm{mV} \mathrm{s}^{-1}$. The curves of $\mathrm{VS}_{2}$ electrode reveal the presence of two redox peaks which are due to the electrochemical redox reactions arising from the presence of oxygen functionalities which have high redox reactivity characteristics in the positive potential window [49]. The observed redox peaks in the $\mathrm{CV}$ curves of $\mathrm{VS}_{2}$ electrode indicates the faradic behavior of the electrode. Furthermore, the GCD curves of $\mathrm{VS}_{2}$ electrode are shown in figure 5(b) at current densities of 0.5, $1,2,3$, and $5 \mathrm{~A} \mathrm{~g}^{-1}$. The discharge curves show potential steps, i.e. a fast potential drop (0.41$0.25 \mathrm{~V})$ and slow potential drop $(0.25-0.18 \mathrm{~V})$ which confirms the faradic behavior of the $\mathrm{VS}_{2}$ electrode as suggested by CV curves. Figure 5(c) shows the CV curves of C-Fe/PANI at different scan rates ranging from 5 to $100 \mathrm{mV} \mathrm{s}^{-1}$. The $\mathrm{CV}$ curves of C-Fe/PANI show relatively rectangular shapes, which is a typical EDLC sample behavior. In addition, the GCD curves of C-Fe/PANI at various current densities ranging from 0.5 to $5.0 \mathrm{~A} \mathrm{~g}^{-1}$ are shown in figure 5(d). These curves show pseudocapacity behavior, thus, illustrating mostly EDLC behavior in agreement with the CV curves of the C-Fe/PANI electrode. Furthermore, for both $\mathrm{VS}_{2}$ and C-Fe/PANI electrode the specific capacitance, $C_{\mathrm{S}}$ of the electrode was calculated from the $\mathrm{CV}$ curves integrals, as shown in figure $5(\mathrm{e})$, using the following equation $[2,50,51]$ :

$$
C_{\mathrm{S}}=\frac{\int I(V) d V}{m v \Delta V}
$$

where $m$ is the total mass of the active material (g), $v$ is the scan rate $\left(\mathrm{V} \mathrm{s}^{-1}\right), \Delta V=V_{\mathrm{f}}-V_{\mathrm{i}}$, and $V_{\mathrm{f}}$ and $V_{\mathrm{i}}$ are the integration potential limits of the $\mathrm{CV}$ curve $(\mathrm{V})$, and $I(\mathrm{~V})$ is the $\mathrm{CV}$ current (A).

In addition, the specific capacity $\left(Q_{\mathrm{S}}\right)$ for both $\mathrm{VS}_{2}$ and C-Fe/PANI electrode showing the EDLC and faradic behavior respectively, was calculated from the GCD curves, as shown in figure 5(f), using the following equation [2,50-53]:

$$
Q_{\mathrm{S}}=\left(\frac{I}{m}\right) \frac{t}{3.6}
$$

where $I$ is the applied current (A), $m$ is the total mass of the active material (g), and $t$ is the time taken for a complete discharge cycle (s). 

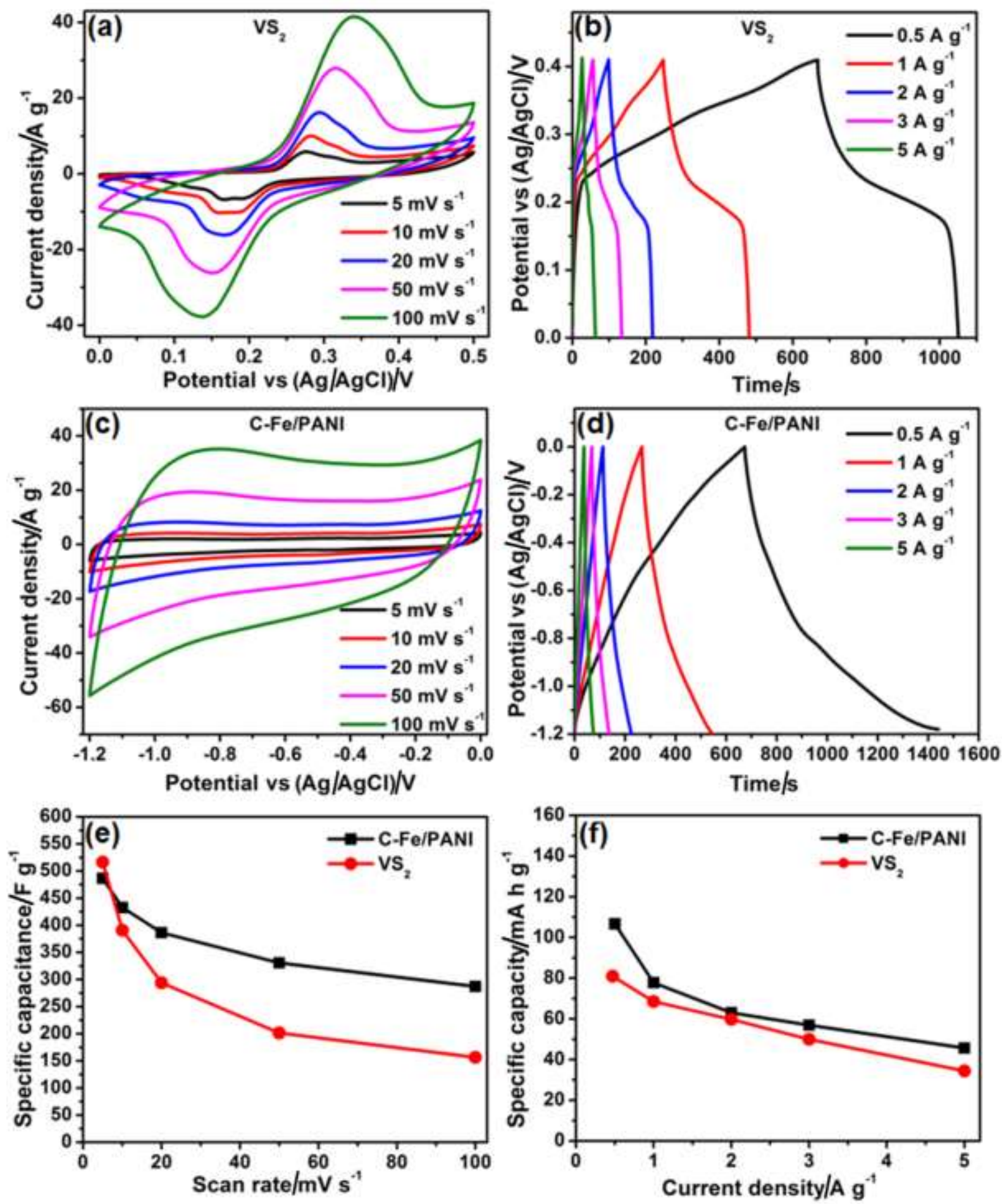

Figure 5. (a) $\mathrm{CV}$ curves of $\mathrm{VS}_{2}$ electrode at different scan rates in a potential window range of 0.0 to $0.5 \mathrm{~V}$. (b) $\mathrm{CD}$ curves of the $\mathrm{VS}_{2}$ electrode at different current densities. (c) CV curves of C-Fe/PANI electrode at different scan rates in a potential window range of -1.2 to $0.0 \mathrm{~V}$. (d) $\mathrm{CD}$ curves of the C-Fe/PANI electrode at different current densities. (e) Specific capacitance as a function of scan rate for both $\mathrm{VS}_{2}$ and C-Fe/PANI electrode. (f) The specific capacity of both C-Fe/PANI and $\mathrm{VS}_{2}$ electrodes as a function of current density. 
In figure 5(e), it can be seen that at a scan rate of $5 \mathrm{mV} \mathrm{s}^{-1}, \mathrm{VS}_{2}$ electrode exhibit a high specific capacitance of $516.5 \mathrm{~F} \mathrm{~g}^{-1}$ than $\mathrm{C}-\mathrm{Fe} / \mathrm{PANI}$ electrode which exhibit a specific capacitance of $486.5 \mathrm{~F} \mathrm{~g}^{-1}$. Additionally, from figure 5(f) it can also be seen that C-Fe/PANI exhibits higher specific capacity than $\mathrm{VS}_{2}$. The specific capacities of C-Fe/PANI and $\mathrm{VS}_{2}$ at current density of $0.5 \mathrm{~A} \mathrm{~g}^{-1}$ are 106.7 and $81.0 \mathrm{~mA} \mathrm{~h} \mathrm{~g}^{-1}$, respectively. It is clear that the specific capacitance and capacity continuously decrease with increasing scan rate and current density for both working electrodes. Generally this may be due to the increasing electronic field within the cell setup, increased by increase in scan rate or current density which alters both Faradic and EDLC processes. In addition, the observed decrease in the specific capacity can also be attributed to the ion exchange mechanism where at low current density, a high specific capacity is obtained because the $\mathrm{OH}^{-}$has enough time to be intercalated/extracted into/out of the electrode during charging/discharging [54]. However, at high current density, a low specific capacity is obtained because less charge is transferred between electrolyte and the electrode. The charge storing capacity of C-Fe/PANI was further compared to carbonized PANI (C-PANI) where the C-PANI electrode was prepared in the similar way as C-Fe/PANI electrode without incorporating Fe. From figure S3 (supporting information), it can be seen that C-PANI charge and discharge faster than $\mathrm{C}-\mathrm{Fe} / \mathrm{PANI}$ electrode which suggest that C-Fe/PANI electrode has a better charge storing capacity signifying that $\mathrm{Fe}$ in $\mathrm{C}-\mathrm{Fe} / \mathrm{PANI}$ enhance electrochemical performance of the electrode.

In addition, the EIS was carried out to evaluate the factors that influence the capacitive performance of the working electrodes such as the electronic resistance of the electrode, an ionic resistance of the electrolyte, the charge-transfer resistance of redox reactions and the diffusive resistance of the electrode in the electrolyte. The EIS was carried out in an open circuit potential and the frequency range of $10-100 \mathrm{mHz}$. To evaluate the cycling performance of the electrodes, the electrodes were subjected to 1000 cycles at a current density of $5 \mathrm{~A} \mathrm{~g}^{-1}$, as shown in figure 6(a). It can be seen that the electrodes show good cycle stability with $100 \%$ columbic efficiency up to 1000 charge-discharge cycles, signifying good electrochemical stability of the electrodes. Figure 6(b) shows the Nyquist plot (imaginary component, $Z^{\prime \prime}$ versus the real component, $Z^{\prime}$ of the impedance) for $\mathrm{VS}_{2}$ before and after stability test. As it can be seen from the plot, $\mathrm{VS}_{2}$ electrode shows electrolyte/solution resistance, $R_{\mathrm{S}}$ value of $0.60 \Omega$ and $0.63 \Omega$ (see inset figure) before and after stability respectively. The observed $R_{\mathrm{S}}$ values before and after cycling stability test are almost equal, hence confirming the good chemical stability of the electrode. For C- 
Fe/PANI electrode, the Nyquist plot is also shown in figure 6(c), and the $R_{\mathrm{S}}$ values are $0.94 \Omega$ and $0.86 \Omega$ before and after stability respectively which are almost equal confirming the good chemical stability of the electrode. Briefly, the $\mathrm{VS}_{2}$ and C-Fe/PANI electrodes show good cycling stability at a high current density of $5 \mathrm{~A} \mathrm{~g}^{-1}$ with $100 \%$ columbic efficiency up to 1000 charge-discharge cycles suggesting that continuous cycling does not cause any structural change on the two electrode materials.
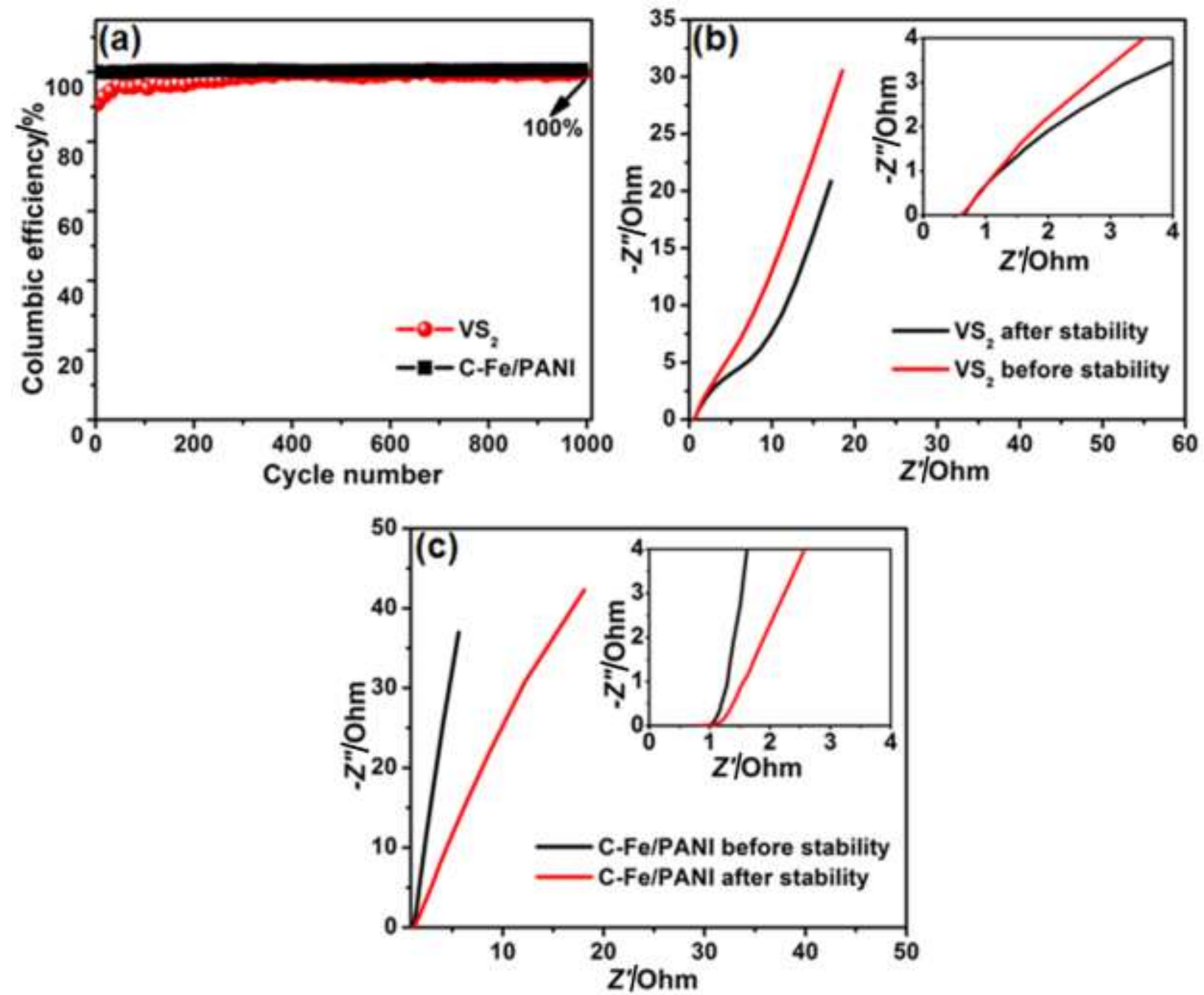

Figure 6. (a) The cycling performance of the $\mathrm{VS}_{2}$ and C-Fe/PANI electrodes at a current density of $5 \mathrm{~A} \mathrm{~g}^{-1}$. The Nyquist plots for the (b) $\mathrm{VS}_{2}$ and (c) C-Fe/PANI electrodes, before and after cycling. The insets show the enlarged high-frequency region of the plots. 
In order to fully explore the electrochemical performance of the $\mathrm{VS}_{2}$ and $\mathrm{C}-\mathrm{Fe} / \mathrm{PANI}$ electrodes, a two-electrode asymmetric device based on $\mathrm{VS}_{2}$ as cathode and C-Fe/PANI as anode was fabricated and investigated by a two-electrode system using $6 \mathrm{M} \mathrm{KOH}$ electrolyte (Figure 7(a)). Due to the difference in the specific capacity of the two electrodes (Figure 5(f)), a charge balance, $Q_{+}=Q_{-}$was done, where $Q_{+}$and $Q_{-}$are charge stored in both positive and negative electrodes respectively, expressed as $Q=C_{S} m \Delta V$. The charge balance is necessary in order to acquire the optimal performance of the device. Based on charge balancing, the mass balance between the positive and negative electrode can be expressed using the following equation [40]:

$$
\frac{m_{+}}{m_{-}}=\frac{C_{\mathrm{S}(-)} \times V_{-}}{C_{\mathrm{S}(+)} \times V_{+}}
$$

where $C_{\mathrm{S}(+)}$ and $C_{\mathrm{S}(-)}$ are the specific capacitance of the active materials in positive and negative electrodes respectively, $m_{+}$and $m_{-}$are the masses of the active materials in positive and negative electrodes and $V_{+}$and $V_{-}$are the potential window of the positive and negative electrodes respectively.

Figure 7(b) shows the $\mathrm{CV}$ curves of both $\mathrm{VS}_{2}$ and $\mathrm{C}-\mathrm{Fe} / \mathrm{PANI}$ electrodes at a scan rate of $50 \mathrm{mV} \mathrm{s}^{-1}$ evaluated in three-electrode. Since the C-Fe/PANI electrode has a potential window range of 0.0 to $-1.2 \mathrm{~V}$ and $\mathrm{VS}_{2}$ of 0.0 to $0.5 \mathrm{~V}$, the $\mathrm{CV}$ curves of $\mathrm{VS}_{2} / / \mathrm{C}-\mathrm{Fe} / \mathrm{PANI}$ asymmetric cell was able to reach potential window range of 0.0 to $1.7 \mathrm{~V}$, as shown in figure $7(\mathrm{c})$ and $7(\mathrm{~d})$. Figure 7(c) shows the CV curves of the device in the potential window of 0.0 to 1.2 and 0.0 to $1.7 \mathrm{~V}$ both at a scan rate of $50 \mathrm{mV} \mathrm{s}^{-1}$. The figure clearly illustrates the EDLC and faradic behavior of the device. It can be seen that the EDLC contribution has equivalent positive and negative currents (i.e. anodic and cathodic reactions), however, the faradic contribution shows much higher positive current (anodic reactions) compared to EDLC contribution suggesting that the contribution of the positive electrode $\left(\mathrm{VS}_{2}\right)$ to the overall current of the device dominates. Consequently, the device has predominantly a battery-like behavior. The CV curves of the device at different scan rates in the range of 5 to $100 \mathrm{mV} \mathrm{s}^{-1}$ are shown in figure 7(d). It can be seen that the CV curves at different scan rates display a combined contribution of EDLC and faradic behaviors which is a typical behavior of hybrid asymmetric supercapacitor. In addition, the GCD curves at different current densities in the range of 2 to $5 \mathrm{~A} \mathrm{~g}^{-1}$ (Figure 7(e)) show potential steps which confirm the faradic behavior of the device as suggested by CV curves 

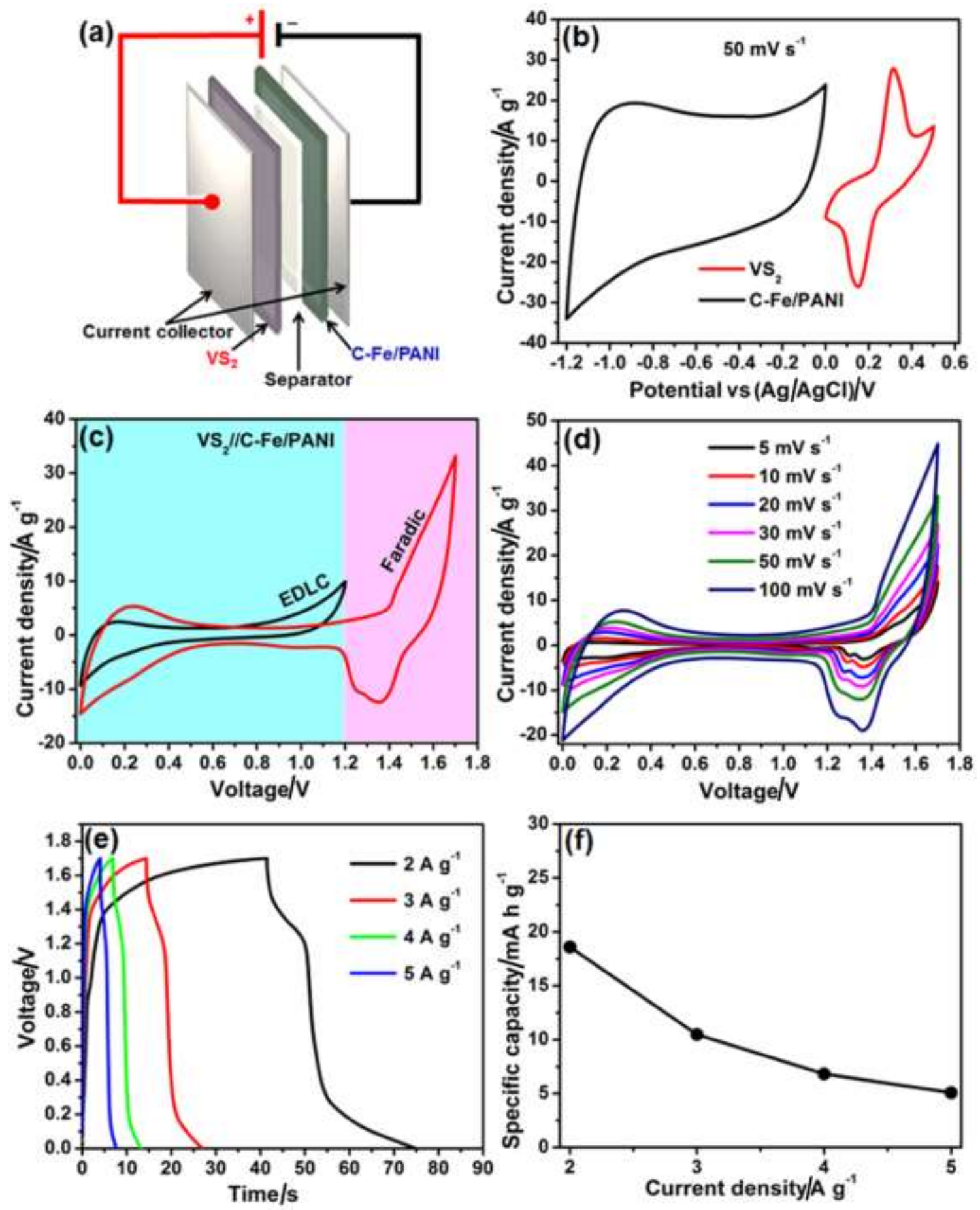

Figure 7. (a) Schematic illustration of the fabricated asymmetric supercapacitor based on $\mathrm{VS}_{2}$ as a cathode and C$\mathrm{Fe} / \mathrm{PANI}$ as an anode in $6 \mathrm{M} \mathrm{KOH}$ aqueous electrolyte. (b) $\mathrm{CV}$ curves of both $\mathrm{VS}_{2}$ and C-Fe/PANI electrodes at a scan rate of $50 \mathrm{mV} \mathrm{s}^{-1}$ evaluated in three-electrode. For the asymmetric $\mathrm{VS}_{2} / / \mathrm{C}-\mathrm{Fe} / \mathrm{PANI}$ device: (c) $\mathrm{CV}$ at scan rates of $50 \mathrm{mV} \mathrm{s}^{-1}$ in the potential window of 0.0 to 1.2 and $1.7 \mathrm{~V}$, (d) CV curves at different scan rates in the range of 5 to $100 \mathrm{mV} \mathrm{s}^{-1}$, and (e) CD curves at different current densities in the range of 0.5 to $10 \mathrm{~A} \mathrm{~g}^{-1}$, (f) the specific capacity as the as a function of current density. 
(Figure 7(d)). Since the device shows mostly faradic behaviour, the specific capacity of the device was calculated from the GCD curves using equation (2) and found to be 19, 10, 7, and $5 \mathrm{~mA} \mathrm{~h} \mathrm{~g}$ at current densities of 2.0, 3.0, 4.0 and $5.0 \mathrm{~A} \mathrm{~g}^{-1}$ respectively (Figure 7(f)). The observed drop in specific capacity with increasing current density could be due to the limited movement of ions by diffusion accessing only the outer surface of the material for charge storage at higher current density [55]. The observed drop in specific capacity values for fabricated device compared to three-electrode measurements, may be due to the increasing electronic field within the cell setup (operated in a high potential window), increased by an increase in current density which alters the synergy of Faradic and EDLC processes. Similar behavior for the $\mathrm{VS}_{2}$-based device can be observed in Ref. 37, for instance, from the GCD curves of the $\mathrm{VS}_{2} / / \mathrm{AC}$ device the specific capacity at current densities of 1.0, 2.0 and $5.0 \mathrm{~A} \mathrm{~g}^{-1}$ are 40,22 and $15 \mathrm{~mA} \mathrm{~h} \mathrm{~g}^{-1}$, respectively.

Moreover, the energy density, $E_{\mathrm{d}}\left(\mathrm{W} \mathrm{h} \mathrm{kg}^{-1}\right)$ and the power density, $P_{\mathrm{d}}\left(\mathrm{W} \mathrm{kg}^{-1}\right)$ were calculated from the GCD curves, as shown in figure 8(a), using the following equations:

$$
\begin{aligned}
& E_{\mathrm{d}}=\left(\frac{I}{m}\right) \frac{\int V(t) d t}{3.6} \\
& P_{\mathrm{d}}=\frac{3.6 E_{\mathrm{d}}}{\Delta t}
\end{aligned}
$$

where $I$ is the applied current (A), $m$ is the total mass of the active material $(\mathrm{g}), \int V(t) d t$ is the integral under the discharge curve from $\mathrm{CD}$ of the device, and $\Delta t$ is the discharge time (s).

The $\mathrm{VS}_{2} / / \mathrm{C}-\mathrm{Fe} / \mathrm{PANI}$ asymmetric device exhibited highest energy and power densities of $27.8 \mathrm{~W}$ $\mathrm{h} \mathrm{kg}^{-1}$ and $2991.5 \mathrm{~W} \mathrm{~kg}^{-1}$ respectively at a current density of $2 \mathrm{~A} \mathrm{~g}^{-1}$. Figure 8(a) shows the Ragone plot of the device which describes the relationship between energy density and power density, including the energy and power density regions for lithium ion batteries (faradic behavior) and electrochemical capacitors (EDLC behavior). Ragone plot clearly shows that the energy densities for $\mathrm{VS}_{2} / / \mathrm{C}$-Fe/PANI asymmetric device are close to the upper end of lithium Ion batteries' region confirming a battery-like behavior of the device. As shown in the Ragone plot, the values obtained in this work are comparable with those found in the previously published 

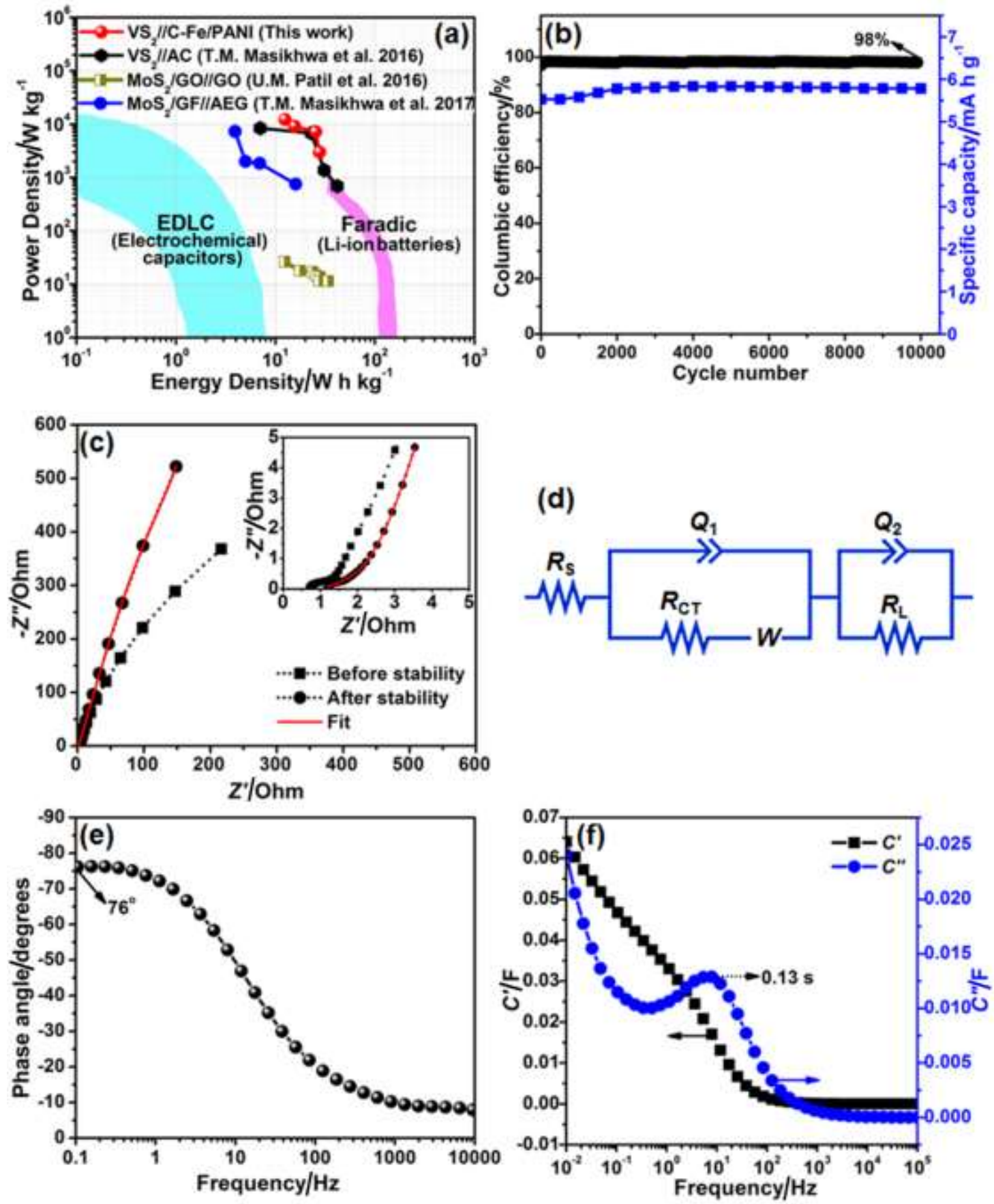

Figure 8. (a) Ragone plot of the $\mathrm{VS}_{2} / / \mathrm{C}$-Fe/PANI asymmetric device showing the relationship between energy and power densities, including the energy and power density regions for lithium ion batteries (Faradic behavior) and electrochemical capacitors (EDLC behavior). (b) The columbic efficiency and the capacity retention and as a function of a cycle number for the device at a current density of $5 \mathrm{~A} \mathrm{~g}^{-1}$. (c) The Nyquist plots before and after cycling stability of the device (the insets show the enlarged high-frequency region of the plots). (d) The equivalent circuit diagram used to fit the Nyquist plot after stability in (c) (i.e. a red solid-line). (e) The phase angle versus frequency. (f) The real and imaginary plot of capacitance as a function of frequency. 
report on $\mathrm{VS}_{2} / / \mathrm{AC}$ asymmetric device [37] and superior to those reported on other metal disulfide based asymmetric devices [56,57].

Figure 8(b) shows the stability test of the device which reveals an excellent cycling stability with a columbic efficiency of $98 \%$ and retains $95 \%$ of its initial capacity up to 10000 cycling at a current density of $5 \mathrm{~A} \mathrm{~g}^{-1}$. To further evaluate the electrochemical behavior of the device (i.e., the conductivity and charge transport properties at the electrode/electrolyte interface), the EIS of the $\mathrm{VS}_{2} / / \mathrm{C}-\mathrm{Fe} / \mathrm{PANI}$ asymmetric device before and after cycling stability was carried out (Figure 8(c)). In figure 8(c), the Nyquist plots (imaginary component, $Z^{\prime \prime}$ versus the real component, $Z^{\prime}$ of the impedance) show negligible semi-circle in the high-frequency region and in the lowfrequency region the plots show a linear component almost parallel to the imaginary axis ( $y$-axis) suggesting nearly ideal behavior of the asymmetric supercapacitor. The Nyquist plots before and after cycling stability are comparable (also see the inset figure) confirming the good chemical stability of the device. The plot after stability was fitted (see a red solid-line in figure 8(c)) using the equivalent circuit diagram shown in figure 8(d). In the high-frequency region, the equivalent circuit diagram presents the equivalent series (solution) resistance, $R_{\mathrm{S}}$ in series with the charge transfer resistance, $R_{\mathrm{CT}}$, and Warburg impedance characteristic element, $W$, which can be expressed as $W=A /(j \omega)^{0.5}$, where $A$ is the Warburg coefficient, $\omega$ is the angular frequency parallel to the real capacitance $\left(Q_{1}\right)$ [58]. The $R_{\mathrm{S}}$ and $R_{\mathrm{CT}}$ values represent the ohmic resistance of the electrodes and the charge-transfer kinetics (fast ion transport) respectively. In the lowfrequency region, an ideal supercapacitor exhibits a vertical line parallel to the imaginary axis with a mass capacitance, $Q_{2}$, however, in practice supercapacitors show deviation from this ideal behavior which is attributed to a leakage resistance, $R_{\mathrm{L}}$ arising from the faradaic charge transfer process $[59,60]$. In the equivalent circuit, $R_{\mathrm{L}}$ is parallel to the $Q_{2}$. The $R_{\mathrm{S}}$ and $R_{\mathrm{CT}}$ values before stability $\left(R_{\mathrm{S}}=0.73 \Omega\right.$ and $\left.R_{\mathrm{CT}}=0.61 \Omega\right)$ and after stability $\left(R_{\mathrm{S}}=1.10 \Omega\right.$ and $\left.R_{\mathrm{CT}}=0.56 \Omega\right)$ are small and similar signifying fast ion diffusion and low charge transfer resistance, hence suggesting nearly an ideal capacitive performance of the device and good chemical stability of the electrodes.

Figure 8(e) shows the impedance phase angle dependence on a frequency Bode plot for the $\mathrm{VS}_{2} / / \mathrm{C}-\mathrm{Fe} / \mathrm{PANI}$ asymmetric device and presents the phase angle value of about $-76^{\circ}$ in the lowfrequency region, which is close to the ideal value of $-90^{\circ}$ suggesting a full capacitive behavior 
of the device. In the low-frequency region, the frequency dependence of the real and imaginary part of the capacitances $\left(C^{\prime}(\omega)\right.$ and $C^{\prime \prime}(\omega)$ ) was evaluated (Figure 8(f)) using a complex capacitance model presented by the following equations [61]:

The impedance, $Z(\varpi)$ given by

$$
Z(\omega)=\frac{1}{j \omega \times C(\omega)}
$$

can be written in the complex form as

$$
Z(\omega)=Z^{\prime}(\omega)+j Z^{\prime \prime}(\omega)
$$

Therefore, equation (6) and (7) gives:

$$
\begin{aligned}
C(\omega) & =\frac{1}{\omega \times\left(j Z^{\prime}(\omega)-Z^{\prime \prime}(\omega)\right)} \\
& =\frac{-\left(Z^{\prime \prime}(\omega)+j Z^{\prime}(\omega)\right)}{\omega|Z(\omega)|^{2}}
\end{aligned}
$$

Thus, $C(\varpi)$ in the complex form can be written as:

$$
C(\omega)=C^{\prime}(\omega)-j C^{\prime \prime}(\omega)
$$

which gives

$$
\begin{aligned}
& C^{\prime}(\omega)=\frac{Z^{\prime \prime}(\omega)}{\omega|Z(\omega)|^{2}} \\
& C^{\prime \prime}(\omega)=\frac{Z^{\prime}(\omega)}{\omega|Z(\omega)|^{2}}
\end{aligned}
$$

where $Z^{\prime}$ and $Z^{\prime \prime}$ are the real part and the imaginary part of the impedance, respectively, defined as

$$
|Z(\omega)|^{2}=Z^{\prime}(\omega)^{2}+Z^{\prime \prime}(\omega)^{2}
$$


and $\omega=2 \pi f . C^{\prime}(\omega)$ is the real accessible capacitance of the cell that can be delivered and this corresponds to the deliverable capacitance of $0.065 \mathrm{~F}$ (Figure 8(f)). $C^{\prime \prime}(\varpi)$ corresponds to energy loss by the irreversible process of the electrodes [61]. In figure 8(f), $C^{\prime \prime}(\omega)$ shows a peak at $8.0 \mathrm{~Hz}$ giving a relaxation time of $0.13 \mathrm{~s}$ which is obtained by taking reciprocal of maximum frequency. This value reveals that the $\mathrm{VS}_{2} / / \mathrm{C}-\mathrm{Fe} / \mathrm{PANI}$ asymmetric device can be fully charged within a very short time.

\section{CONCLUSION}

In this work, $\mathrm{VS}_{2}$ nanosheets electrode material was successfully synthesized by the hydrothermal method, and the C-Fe/PANI electrode material was directly synthesized on a current collector by pyrolysis of the iron-PANI mixture coated on nickel foam in a tube furnace under the $\mathrm{N}_{2}$ atmosphere. The structural and morphological characterization of the assynthesized $\mathrm{VS}_{2}$ electrode showed characteristic XRD peaks of $\mathrm{VS}_{2}$. Furthermore, the Raman and FTIR vibration spectra also showed the characteristic vibration bands of $\mathrm{VS}_{2}$. The SEM images of the $\mathrm{VS}_{2}$ sample showed that is composed of a large number of nanosheets. Similarly, the structural and morphological characterization of C-Fe/PANI electrode confirmed diffraction peaks of $\mathrm{Fe}, \mathrm{Fe}_{3} \mathrm{C}, \mathrm{FeS}$ and a broad diffraction peak of graphitized PANI. The Raman and FTIR vibration spectra of $\mathrm{C}$-Fe/PANI revealed features of the graphitized carbon material, PANI functional groups, and Fe-PANI vibration bands. The SEM images of the C-Fe/PANI sample showed agglomerated nanograins. The electrochemical behavior of each working electrode was analyzed in a three-electrode cell configuration using $6 \mathrm{M} \mathrm{KOH}$ electrolyte, and thereafter, an asymmetric device was successfully fabricated using $\mathrm{VS}_{2}$ nanosheets as the positive electrode and $\mathrm{C}-\mathrm{Fe} / \mathrm{PANI}$ as a negative electrode. The fabricated $\mathrm{VS}_{2} / / \mathrm{C}-\mathrm{Fe} / \mathrm{PANI}$ asymmetric device was found to perform at a high applied potential difference of $1.7 \mathrm{~V}$ in $6 \mathrm{M} \mathrm{KOH}$. At a current density of $2 \mathrm{~A} \mathrm{~g}^{-1}$, the device exhibited a maximum energy and power densities of $27.8 \mathrm{Wh} \mathrm{kg}^{-1}$ and $2991.5 \mathrm{~W} \mathrm{~kg}^{-1}$ respectively. In addition, a $\mathrm{VS}_{2} / / \mathrm{C}-\mathrm{Fe} / \mathrm{PANI}$ device showed excellent cycling stability with $95 \%$ capacity retention over 10000 galvanostatic charge-discharge cycles at a current density of $5 \mathrm{~A} \mathrm{~g}^{-1}$. 


\section{ACKNOWLEDGEMENTS}

This work is based on research supported by the South African Research Chairs Initiative (SARChI) of the Department of Science and Technology and the National Research Foundation (NRF) of South Africa (Grant No. 61056). Any opinion, finding and conclusion or recommendation expressed in this material is that of the author(s) and the NRF does not accept any liability in this regard. Mologadi N. Rantho acknowledges the financial support from University of Pretoria and NRF through SARChI in Carbon Technology and Materials.

\section{REFERENCES}

[1] G. Feng, S. Li, V. Presser, P.T. Cummings, Molecular Insights into Carbon Supercapacitors Based on Room-Temperature Ionic Liquids, J. Phys. Chem. Lett. 4 (2013) 3367-3376. doi:10.1021/jz4014163.

[2] P. Simon, Y. Gogotsi, Materials for electrochemical capacitors, Nat. Mater. 7 (2008) 845-854. doi:10.1038/nmat2297.

[3] K. Zhang, L.L. Zhang, X.S. Zhao, J. Wu, Graphene/Polyaniline Nanofiber Composites as Supercapacitor Electrodes, Chem. Mater. 22 (2010) 1392-1401. doi:10.1021/cm902876u.

[4] D.A.C. Brownson, D.K. Kampouris, C.E. Banks, An overview of graphene in energy production and storage applications, J. Power Sources. 196 (2011) 4873-4885. doi:10.1016/j.jpowsour.2011.02.022.

[5] Y. Xie, Z. Song, S. Yao, H. Wang, W. Zhang, Y. Yao, B. Ye, C. Song, J. Chen, Y. Wang, High capacitance properties of electrodeposited PANI-Ag nanocable arrays, Mater. Lett. 86 (2012) 77-79. doi:10.1016/j.matlet.2012.07.026.

[6] W. Sun, X. Chen, Fabrication and tests of a novel three dimensional micro supercapacitor, Microelectron. Eng. 86 (2008) 1307-1310. doi:10.1016/j.mee.2008.12.010.

[7] D.P. Dubal, S.V. Patil, W.B. Kim, C.D. Lokhande, Supercapacitors based on electrochemically deposited polypyrrole nanobricks, Mater. Lett. 65 (2011) 2628-2631. doi:10.1016/j.matlet.2011.05.114. 
[8] B.E. Conway, Electrochemical Supercapacitors Scientific Fundamentals and Technological Applications 1999.pdf, Kluwer Academic/Plenum: New York, 1999.

[9] J.R.J. Miller, A.F.A. Burke, Electrochemical capacitors: challenges and opportunities for realworld applications, Electrochem. Soc. Interface. 17 (2008) 53.

[10] A. Burke, R\&D considerations for the performance and application of electrochemical capacitors, Electrochim. Acta. 53 (2007) 1083-1091. doi:10.1016/j.electacta.2007.01.011.

[11] G. Feng, S. Li, V. Presser, P.T. Cummings, Molecular Insights into Carbon Supercapacitors Based on Room-Temperature Ionic Liquids, J. Phys. Chem. Lett. 4 (2013) 3367-3376. doi:10.1021/jz4014163.

[12] X. Rui, H. Tan, Q. Yan, Nanostructured metal sulfides for energy storage, Nanoscale. 6 (2014) 9889. doi:10.1039/C4NR03057E.

[13] G. Zhang, M. Kong, Y. Yao, L. Long, M. Yan, One-pot synthesis of $\gamma-M n S$ / reduced graphene oxide with enhanced performance for aqueous asymmetric supercapacitors, Nanotechnology 28 (2017) 065402. doi:10.1088/1361-6528/aa52a5.

[14] D.S. Patil, J.S. Shaikh, S.A. Pawar, R.S. Devan, Y.R. Ma, A.V. Moholkar, J.H. Kim, R.S. Kalubarme, C.J. Park, P.S. Patil, Investigations on silver/polyaniline electrodes for electrochemical supercapacitors, Phys. Chem. Chem. Phys. Phys. Chem. Chem. Phys. 14 (2012) 11886-11895. doi:10.1039/c2cp41757j.

[15] S.K. Mondal, K. Barai, N. Munichandraiah, High capacitance properties of polyaniline by electrochemical deposition on a porous carbon substrate, Electrochim. Acta. 52 (2007) 32583264. doi:10.1016/j.electacta.2006.09.067.

[16] H. Mi, X. Zhang, X. Ye, S. Yang, Preparation and enhanced capacitance of core-shell polypyrrole/ polyaniline composite electrode for supercapacitors, J. Power Sources. 176 (2008) 403-409. doi:10.1016/j.jpowsour.2007.10.070.

[17] C. Portet, P.L. Taberna, P. Simon, E. Flahaut, C. Laberty-Robert, High power density electrodes for Carbon supercapacitor applications, Electrochim. Acta. 50 (2005) 4174-4181. doi:10.1016/j.electacta.2005.01.038. 
[18] M. Sawangphruk, M. Suksomboon, K. Kongsupornsak, J. Khuntilo, P. Srimuk, Y. Sanguansak, P. Klunbud, P. Suktha, P. Chiochan, High-performance supercapacitors based on silver nanoparticle-polyaniline-graphene nanocomposites coated on flexible carbon fiber paper, J. Mater. Chem. A. 1 (2013) 9630. doi:10.1039/c3ta12194a.

[19] K.S. Ryu, K.M. Kim, N.G. Park, Y.J. Park, S.H. Chang, Symmetric redox supercapacitor with conducting polyaniline electrodes, J. Power Sources. 103 (2002) 305-309. doi:10.1016/S03787753(01)00862-X.

[20] S. Zhou, H. Zhang, Q. Zhao, X. Wang, J. Li, F. Wang, Graphene-wrapped polyaniline nanofibers as electrode materials for organic supercapacitors, Carbon. 52 (2013) 440-450. doi:10.1016/j.carbon.2012.09.055.

[21] M. Sawangphruk, T. Kaewsongpol, Direct electrodeposition and superior pseudocapacitive property of ultrahigh porous silver-incorporated polyaniline films, Mater. Lett. 87 (2012) 142145. doi:10.1016/j.matlet.2012.07.103.

[22] A. Clemente, S. Panero, E. Spila, B. Scrosati, Solid-state, polymer-based, redox capacitors, Solid State Ion. 85 (1996) 273-277. doi: 10.1016/0167-2738(96)00070-7.

[23] A. Sarkar, P. Ghosh, A.K. Meikap, S.K. Chattopadhyay, S.K. ChatterjeeM Ghosh, S.K. Chatterjee, M. Ghosh, Alternate and direct current conductivity of conducting polyaniline dispersed with poly vinyl alcohol and blended with methyl cellulose, J. Appl. Phys. 97 (2005) 113713. doi:10.1063/1.1923168.

[24] S.S. Umare, B.H. Shambharkar, R.S. Ningthoujam, Synthesis and characterization of polyaniline- $\mathrm{Fe}_{3} \mathrm{O}_{4}$ nanocomposite: Electrical conductivity, magnetic, electrochemical studies, Synth. Met. 160 (2010) 1815-1821. doi:10.1016/j.synthmet.2010.06.015.

[25] H. Wang, Y. Liang, M. Gong, Y. Li, W. Chang, T. Mefford, J. Zhou, J. Wang, T. Regier, F. Wei, H. Dai, An ultrafast nickel-iron battery from strongly coupled inorganic nanoparticle/nanocarbon hybrid materials, Nat. Commun. 3 (2012) 917. doi:10.1038/ncomms1921.

[26] Q. Qu, S. Yang, X. Feng, 2D sandwich-like sheets of iron oxide grown on graphene as high energy anode material for supercapacitors, Adv. Mater. 23 (2011) 5574-5580. 
doi:10.1002/adma.201103042.

[27] Z. Liu, S.W. Tay, X. Li, Rechargeable battery using a novel iron oxide nanorods anode and a nickel hydroxide cathode in an aqueous electrolyte, Chem. Commun. 47 (2011) 12473. doi:10.1039/c1cc15022g.

[28] B. Yanwu Zhu, S. Murali, W. Cai, X. Li, J. Won Suk, J.R. Potts, R.S. Ruoff, Graphene and Graphene Oxide: Synthesis, Properties, and Applications, Adv. Mater. 22 (2010) 3906-3924. doi:10.1002/adma.201001068.

[29] J. Wang, B. Deng, H. Chen, X. Wang, J. Zheng, Removal of Aqueous Hg(II) by Polyaniline: Sorption Characteristics and Mechanisms, Environ. Sci. Technol. 43 (2009) 5223-5228. doi:10.1021/es803710k.

[30] J. Zhang, C. Liu, G. Shi, Raman spectroscopic study on the structural changes of polyaniline during heating and cooling processes, J. Appl. Polym. Sci. 96 (2005) 732-739. doi:10.1002/app.21520.

[31] Y. Tang, T. Chen, S. Yu, Y. Qiao, S. Mu, J. Hu, F. Gao, Synthesis of graphene oxide anchored porous manganese sulfide nanocrystals via the nanoscale Kirkendall effect for supercapacitors, J. Mater. Chem. A. 3 (2015) 12913-12919. doi:10.1039/C5TA02480C.

[32] P.C. Chen, G. Shen, Y. Shi, H. Chen, C. Zhou, Preparation and Characterization of Flexible Asymmetric Supercapacitors Based on Transition-Metal-Oxide Nanowire/Single-Walled Carbon Nanotube Hybrid Thin-Film Electrodes, ACS Nano. 4 (2010) 4403-4411. doi:10.1021/nn100856y.

[33] Y. Tang, T. Chen, S. Yu, Y. Qiao, S. Mu, S. Zhang, Y. Zhao, L. Hou, W. Huang, F. Gao, A highly electronic conductive cobalt nickel sulphide dendrite/quasi-spherical nanocomposite for a supercapacitor electrode with ultrahigh areal specific capacitance, J. Power Sources. 295 (2015) 314-322. doi:10.1016/j.jpowsour.2015.07.035.

[34] Y. Tang, T. Chen, S. Yu, Morphology controlled synthesis of monodispersed manganese sulfide nanocrystals and their primary application in supercapacitors with high performances, Chem. Commun. 51 (2015) 9018-9021. doi:10.1039/C5CC01700A.

[35] T. Chen, Y. Tang, Y. Qiao, Z. Liu, W. Guo, J. Song, S. Mu, S. Yu, Y. Zhao, F. Gao, All-solid- 
state high performance asymmetric supercapacitors based on novel $\mathrm{MnS}$ nanocrystal and activated carbon materials, Sci. Rep. 6 (2016) 23289. doi:10.1038/srep23289.

[36] J. Feng, X. Sun, C. Wu, L. Peng, C. Lin, S. Hu, J. Yang, Y. Xie, Metallic few-layered VS 2 ultrathin nanosheets: High two-dimensional conductivity for in-plane supercapacitors, J. Am. Chem. Soc. 133 (2011) 17832-17838. doi:10.1021/ja207176c.

[37] T.M. Masikhwa, F. Barzegar, J.K. Dangbegnon, A. Bello, M.J. Madito, D. Momodu, N. Manyala, Asymmetric supercapacitor based on $\mathrm{VS}_{2}$ nanosheets and activated carbon materials, RSC Adv. 6 (2016) 38990. doi:10.1039/C5RA27155J.

[38] G.A. Wiegers, Physical properties of first-row transition metal dichalcogenides and their intercalates, Phys. B+C. 99 (1980) 151-165. doi:10.1016/0378-4363(80)90225-9.

[39] M. Zhao, H. Song, Synthesis of carbon-encapsulated iron carbide/iron nanoparticles from phenolic-formaldehyde resin and ferric nitrate, Mater. Chem. Phys. 124 (2010) 861-864. doi:10.1016/j.matchemphys.2010.08.011.

[40] N. Daems, X. Sheng, Y. Alvarez-Gallego, I.F.J. Vankelecom, P.P. Pescarmona, Ironcontaining $\mathrm{N}$-doped carbon electrocatalysts for the cogeneration of hydroxylamine and electricity in a $\mathrm{H}_{2}-\mathrm{NO}$ fuel cell, Green Chem. 18 (2016) 1547-1559. doi:10.1039/C5GC02197A.

[41] S. Sugai, K. Murase, S. Uchida, S. Tanaka, Studies of lattice dynamics in $2 \mathrm{H}-\mathrm{TaS}_{2}$ by Raman scattering, Solid State Commun. 40 (1981) 399-401. doi:10.1016/0038-1098(81)90847-4.

[42] W.G. McMullan, J.C. Irwin, Raman scattering from $2 \mathrm{H}$ and $3 \mathrm{R}-\mathrm{NbS}_{2}$, Solid State Commun. 45 (1983) 557-560. doi:10.1016/0038-1098(83)90426-X.

[43] C. Röder, T. Weißbach, C. Himcinschi, J. Kortus, S. Dudczig, C.G. Aneziris, Raman spectroscopic characterization of novel carbon-bonded filter compositions for steel melt filtration, J. Raman Spectrosc. 45 (2014) 128-132. doi:10.1002/jrs.4426.

[44] S.K. Pradhan, B.B. Nayak, B.K. Mohapatra, B.K. Mishra, Micro Raman Spectroscopy and Electron Probe Microanalysis of Graphite Spherulites and Flakes in Cast Iron, Metall. Mater. Trans. A. 38 (2007) 2363-2370. doi:10.1007/s11661-007-9288-1. 
[45] Y. Ren, N. Yan, J. Feng, J. Ma, Q. Wen, N. Li, Q. Dong, Adsorption mechanism of copper and lead ions onto graphene nanosheet/ $\delta-\mathrm{MnO}_{2}$, Mater. Chem. Phys. 136 (2012) 538-544. doi:10.1016/j.matchemphys.2012.07.023.

[46] Y. Zhao, H. Ma, S. Huang, X. Zhang, M. Xia, Y. Tang, Z.F. Ma, Monolayer Nickel Cobalt Hydroxyl Carbonate for High Performance All-Solid-State Asymmetric Supercapacitors, ACS Appl. Mater. Interfaces. 8 (2016) 22997-23005. doi:10.1021/acsami.6b05496.

[47] R. Li, Z. Hu, X. Shao, P. Cheng, S. Li, W. Yu, W. Lin, D. Yuan, Large Scale Synthesis of NiCo Layered Double Hydroxides for Superior Asymmetric Electrochemical Capacitor., Sci. Rep. 6 (2016) 18737. doi:10.1038/srep18737.

[48] Y. He, J. Pan, L. Wu, Y. Zhu, X. Ge, J. Ran, Z. Yang, T. Xu, A Novel Methodology to Synthesize Highly Conductive Anion Exchange Membranes, Sci. Rep. 5 (2015). doi:10.1038/srep13417.

[49] K.O. Oyedotun, M.J. Madito, A. Bello, D.Y. Momodu, A.A. Mirghni, N. Manyala, Electrochimica Acta Investigation of graphene oxide nanogel and carbon nanorods as electrode for electrochemical supercapacitor, Electrochim. Acta. 245 (2017) 268-278. doi:10.1016/j.electacta.2017.05.150.

[50] B. Akinwolemiwa, C. Peng, G.Z. Chen, Redox electrolytes in supercapacitors, J. Electrochem. Soc. 162 (2015) A5054-A5059. doi:10.1149/2.0111505jes.

[51] A. Laheäär, P. Przygocki, Q. Abbas, F. Béguin, Appropriate methods for evaluating the efficiency and capacitive behavior of different types of supercapacitors, Electrochem. Commun. 60 (2015) 21-25. doi:10.1016/j.elecom.2015.07.022.

[52] K.O. Oyedotun, M.J. Madito, A. Bello, D.Y. Momodu, A.A. Mirghni, N. Manyala, Investigation of graphene oxide nanogel and carbon nanorods as electrode for electrochemical supercapacitor, Electrochim. Acta. (2017). doi:10.1016/j.electacta.2017.05.150.

[53] G. Godillot, L. Guerlou-Demourgues, P.L. Taberna, P. Simon, C. Delmas, Original Conductive Nano- $\mathrm{Co}_{3} \mathrm{O}_{4}$ Investigated as Electrode Material for Hybrid Supercapacitors, Electrochem. Solid-State Lett. 14 (2011) A139. doi:10.1149/1.3609259.

[54] C. Yuan, X. Zhang, L. Su, B. Gao, L. Shen, Facile synthesis and self-assembly of hierarchical 
porous $\mathrm{NiO}$ nano/micro spherical superstructures for high performance supercapacitors, J. Mater. Chem. 19 (2009) 5772-5777. doi:10.1039/B902221J.

[55] D.Y. Momodu, F. Barzegar, A. Bello, J. Dangbegnon, T. Masikhwa, J. Madito, N. Manyala, Simonkolleite-graphene foam composites and their superior electrochemical performance, Electrochim. Acta. 151 (2015) 591-598. doi:10.1016/j.electacta.2014.11.015.

[56] U.M. Patil, M.S. Nam, S. Kang, J.S. Sohn, H.B. Sim, S. Kang, S.C. Jun, Fabrication of ultrahigh energy and power asymmetric supercapacitors based on hybrid 2D $\mathrm{MoS}_{2}$ /graphene oxide composite electrodes: a binder-free approach, RSC Adv. 6 (2016) 43261-43271. doi:10.1039/c6ra00670a.

[57] T.M. Masikhwa, M.J. Madito, A. Bello, J.K. Dangbegnon, N. Manyala, High performance asymmetric supercapacitor based on molybdenum disulphide/graphene foam and activated carbon from expanded graphite, J. Colloid Interface Sci. 488 (2017) 155-165. doi:10.1016/j.jcis.2016.10.095.

[58] Y. Zhou, H. Xu, N. Lachman, M. Ghaffari, S. Wu, Y. Liu, A. Ugur, K.K. Gleason, B.L. Wardle, Q.M. Zhang, Advanced asymmetric supercapacitor based on conducting polymer and aligned carbon nanotubes with controlled nanomorphology, Nano Energy. 9 (2014) 176-185.

[59] W. Sun, X. Chen, Preparation and characterization of polypyrrole films for three-dimensional micro supercapacitor, J. of Power Sources 193 (2009) 924-929. doi:10.1016/j.jpowsour.2009.04.063.

[60] H. Li, J. Wang, Q. Chu, Z. Wang, F. Zhang, S. Wang, Theoretical and experimental specific capacitance of polyaniline in sulfuric acid, J. of Power Sources 190 (2009) 578-586. doi:10.1016/j.jpowsour.2009.01.052.

[61] P.L. Taberna, P. Simon, J.F.F. Fauvarque, Electrochemical Characteristics and Impedance Spectroscopy Studies of Carbon-Carbon Supercapacitors, J. Electrochem. Soc. 150 (2003) A292-300. doi:10.1149/1.1543948. 